\title{
A detailed Study on Data Centre Energy Efficiency and Efficient Cooling Techniques
}

\author{
Dibyendu Mukherjee $^{1}$, Srabanti Chakraborty ${ }^{2}$, Indranil Sarkar ${ }^{3}$, Ahona Ghosh ${ }^{4}$, Sandip Roy $^{5}$ \\ ${ }^{1}$ Brainware University, India, dibs.tech18@gmail.com \\ ${ }^{2}$ Elitte Institute of Engineering \& Management, India, srabanti2k@gmail.com \\ ${ }^{3}$ Brainware University, India, indra.nil2004@gmail.com \\ ${ }^{4}$ Brainware University, India, ahonaghosh95@gmail.com \\ ${ }^{5}$ Brainware University, India, sandiproy86@gmail.com
}

\begin{abstract}
In this era of modern technology, the cloud computing is considered as the most vibrant and indispensable part of the world of Information \& Communication Technologies which is shaping the modern networking technology by introducing a new door with technical experiments for conserving the environment. It is empowered to rise the energy efficiency by reducing the carbon emissions that leads the transformation of cloud computing into green cloud computing. The buzzword term "Green cloud" is the combination of two terms "green" and "cloud" to symbolized the concept of ecofriendly environment with the Internet that is basically known as cloud computing. Even though the immense power of modern technology already gripped the environment and destroying the nature and environment that is not a renewable resource and it obvious has a great impact on life. Therefore it rises the awareness regarding environmental impact of the computing and so that green technology is gaining the importance accordingly. In this survey paper, we define a systematic approach to analyse different data centres' energy efficiency along with the concepts of diminishing the cost of the data centres by utilizing the cooling systems efficiently.
\end{abstract}

Key words: Carbon Emission, Cloud Data Centres, Cooling Systems, Green Cloud Computing.

\section{INTRODUCTION}

Highlight nowadays the fast and innovative technologies are changing the IT world so quickly that the cloud concept is becoming an essential and integral part of the technical world. All the enterprises are seeking for the cloud concept due to the attractive characteristics of cloud. The cloud provides various ranges of services including the high performance computing to storage. Cloud data centre plays a significant role for cloud application as the cloud data centre contains different entities namely servers, networks, cooling systems, wires to carry several information towards the servers. Even though the cloud computing is widely used for data centres but it leads a danger on environment by introducing heavy energy consumption, heat emission, releasing the toxic gaseous.

As per the view of Laura-Diana Radu [2], due to fast growth of energy consumption the concept of sustainability is playing an important role among the users and developers of software and hardware in last few years. To save the environment and to maintain the green, the impact of ICTs (information and communication technologies) on the environment throughout the life has been studied. These may influence to the improvement and saving of the recent scenario of the environment by weakening harmful and adverse effects that have increased during the last few years. According to Koomey [3] the data centres consumed the $1.3 \%$ of the total consumption in 2010. As per report published by GeSI [4], total CO2 discharges from ICTs raises from 1.3\% in 2002 to $2.3 \%$ in 2020. According to Amlan Deep Borah.et.al. [5] due to the environmental, economic and marketing aspects of energy in various field, the concept of energy saving is getting importance and becoming a key issue which has a strong impact on IT and networking sectors. As the Networking sector and data-centre contains high-availability and high-performance devices so they need powerful devices with high energy consumption that requires air condition to maintain their regular operation. Various research states that ICT generates $3 \%$ of global energy and $2 \%$ of global CO2 discharges expenditure from the energy and environmental point of view [6]. Maximum amount of energy is consumed by data centres in ICT [5]. Almost 30\% of the total power consumption that is used for computation is consumed by network infrastructure of a data centre. It is basically composed of switches and links.

The concept of cooling technology is the most significant approach for green computing. Massive energy consumption of data centres and consequent increasing cost of data centres can be reduced by the implementation of effective cooling technology and can generate maximum profit accordingly. 
The data centre required a technique in which the cold air enters from the front side and excluded from the back side. It also maintains the flow of cold air by keeping the doors to the room closed.

As the data centres generates a huge amount of heat in every day so it becoming a significant issue that must be taken care of [7]. The data centres are facing the problem regarding the raising of the operational cost due to rapid uses of expensive compressor based cooling system and extreme heat generation accordingly. Repeated uses of same air is one of the typical way to cooling the compressor. In this process the cold air is moved to servers for absorbing their heat, then discharged by fans and cooled by compressors and back to the servers again.

The concept of free cooling provides a little bit changes in the equation as the air once gets hot in the servers, then it's released fully or partially into the environment and then the cold air is moved into its place. In various regions of world, due to this smart technique, sometimes it is not required to cool the hot air in the compressors as for most of the year the outside air is cooler than the inside temperature of data centre. It signifies that the entire process may get rid of the maximum energy consumption part. That is reason that the approach of free cooling has gripped the data centres and is rapidly it becoming the new norm [8]. In this free cooling system it is not required to cold the hot air as the cold air comes into the data centre from outside. By adopting the free cooling method, The Data Centre Providers (DCPs) may offer their amenities in low-priced rate as this free cooling system allows the data centres to save a massive energy that minimize the cost. Finally this technique helps to move towards the greener environment through the less energy consumption consumed by the data centres.

\section{LITERATURE REVIEW}

As part of our research analysis on "A detailed study on Data Centre Energy Optimization and Efficient Cooling Technique", we systematically verified many journals, conferences, white papers, web sources to get the valid content about the Cooling methods, Energy Efficiency approaches of Data Centres and their characteristics. In this section we present the literature review on green cloud computing with the help of its relevant former research publications. In this analysis, each research activities in the area of reducing energy consumption and different cooling methods are explored in brief with author details. This information helps the research scholars to understand the significance and evaluation of the green cloud computing. It also focuses on the improvements. The survey also emphasis on different areas namely Recycling of E-Waste, Energy Consumption, Consolidation and Optimization of Data Centre, Data Centre Cooling technology and Virtualization.

Ruhi D. Viroja et al [10] proposed some techniques which can minimize the power consumption. More energy efficient techniques of data centres are proposed by Usvuv et al [11]. Sharma [12] described the study on Green Computing to explore the efficient development of effective computer programs by using all the available cores of a CPU to get a fast execution as compared to other single-core implementation of the program which further results in energy savings. Beside this, there is also a case study included as a supporting of the study. Apart from that, the study also indicated that the multi core approach displayed superior skill and presentation when the total number of computation is more otherwise the performance is inferior as compared to the single-core computation. Kharchenko et al. [13] described the classification of green IT engineering with notions. This paper also analyses the most important primary principles of development and application, explains the indicators and values of green computing and describes the European Union project Green Co. More et al. [14] stressed on several techniques with different algorithms and models for the implementation of green cloud computing with an efficient virtualization method. The study mainly includes the consolidation of VM. This paper stated that depending on the demand of workload, the power consumption can be minimized by deactivating and reactivating the physical machines. Several approaches discussed in this paper to $t$ depict the concept of saving the power for making an effective and efficient data centre. Sharma et al. [15] presented the strategy and analysis of a green university data centre and also offers different insight into the various operational and competency characteristics.

Mesaad et al. [16] provided an analysis of the current green computing initiatives and an overall comparison between them to show their efficiency. HP program is the greenest computing waste-management initiatives from the point of e-waste management. Considering Energy consumption, the Energy Star and EPEAT initiatives happen to be the most successful program based on the latest energy savings statistics and their users trusted labeling. AlMusbahi et al. [17] discussed about the developments and challenges of green computing. Kern [18] discussed about awareness and approaches of creating awareness on green computing with emphasis on green software along with a user survey.

Fisher et al. [19], suggested in his article that as the several links of core networks are basically "bundles" of multiple physical cables and line cards so this is required to turn off the cables and the NICs (Network Interface Cards) individually in contrast to putting off the links. Three heuristics namely Greedy Heuristic, Exhaustive Greedy Heuristic, and Bi-level Greedy Heuristic are proposed by the authors in this paper, to solve the problem. Savings of $79 \%$ energy bundles of five cables in each link has been shown by this paper.

According to the view of [20], a network oriented approach DENS that can be an effective approach for making the energy efficient scheduling with an effective approach for a data centres, regarding the consumption power of energy by 
decreasing the energy consumption power through scheduling the jobs to computing resources as per the effective and best fit algorithm. It can be achieved while receive the load level and the communication development of the different components of the network system. Its key objective is to eliminate the overcrowding at the time of reducing the computer servers for meeting the requirement of QoS needed for job when the consumption rate of energy will be increased slightly.

Abdul Majid Farooqi [21] in his review article described several methods of green cloud computing with the approximate results. In this article he was represent some techniques to reduce the energy efficiency. He defined various designs that can be applied in home. These are mainly Hard disk sleep mode, LED/LCD sleep mode. The article suggested switching off all the devices when not currently being in used and always using the power saver mode to save energy. In case of Data Centres, to enable or disable a clock use "clock gating technology'. This technology is considered as very effective way for minimizing the rate of power that consumed by the IT devices of a data centre, by restricting the use of processors, buses, controllers and bridges. It helps to save the electrical power used by the processor. Use of energy efficient processor and energy efficient storage is another technique to consume the less power and implementation of the solar technology is another helping approach to reduce the volume of power to be consumed by the data centres.

According to [22], for reducing the problem which arises due to the consumption of huge energy in the data centre, there can be implemented an Integer Linear Programming model for developing an algorithm of dynamic task scheduling. He also focused on the presenting of an Adaptive Genetic Algorithm to depict dynamic characteristics which are related with Cloud platform. As per his report, this algorithm also offers a solution that deals with optimal scheduling to decrease the energy consumed by data centre. The proposed algorithm is affirmed by simulation of Cloud infrastructure and leading a quality evaluation study with set of tasks for environment.

Ruihong LIN et.al. [23], offers a method of balancing between the power of computing and cooling power to diminish the power consumption rate that consumed by the data centres. $\mathrm{He}$ also suggested to implement an EGA (enhanced genetic algorithm) for exploring solution space of the power model which is a model of is a liner programming problem. The concept of EGA may be the causes of reducing the performance with the growth of the problem size as EGA is computing intensive. As per the article, the application of HGS or heuristic greedy sequence is better in contrast to enhanced genetic algorithm as it is capable to calculate the allocation of workload of a specific data centre layout by applying a single calculation which leads a result to show that application of both the HGS and EGA is able to minimize the power consumption of data centres in comparison to the random algorithm. Furthermore, in this article, the authors represent a total power model for assigning the workload in the data centre in an efficient manner. Antonios $\mathrm{T}$. Makaratzis et.al. [24], emphasis on different proposed energy models for predicting the rate of energy consumption, consumed by various devices of data centres like memory, CPU, network and storage at the time of on-going experiments to compare between several power models that are used by different simulation frameworks like CloudSim, GreenCloud, CloudSched, iCanCloud and so on.

Dr. Bhubaneswari Bisoyi et.al. [25], depicts the importance and significant impact of green computing concept and its application and also shows the essential steps that can be maintained by the business process, organizations to establish a healthy and green atmosphere. As per their view, the proposed concept can be an effective solution to control the increasing pollution due to several causes by reducing the toxic effects of carbon foot print around the environment. Walter Binder et.al. [26] presented a method to support the task of servers by improving the effectiveness of the energy of data centres and also try to shut down the server nodes which are not in use. Giuseppe Procaccianti et.al. [27] suggested various techniques of hardware and software architecture for resolving the problems and started to analysis of the art and power of the energy efficient cloud computing software solutions. Although their proposed paper could not show the complete solution that can be considered as service level objective. In this study, they have only represented some approaches of software architecture for addressing the energy efficiencies. According to analysis on computing in a green environment, Shailesh Saxena et.al. [28], proposed that there are four regions which contain as the power efficiency advantages for cloud computing and these are: Diversity, Economies of Scale, Flexibility and Enabling Structural Change. Here, diversity allows to spread the computing loads across huge users and hardware utilization can be improved by time zones. The area of economies of Scale can introduce the concept of inexpensive computation in a large shop rather than small shop due to spreading of fixed cost among many servers and users. The area of flexibility tells that in the cloud, handling the virtual server is more simple and inexpensive than handling physical servers and the fourth area of enabling structural change is the feature that states that working with cloud platform in a business can reduce the costing and save money. Soha Rawas et.al] focused on the need and effectiveness of Cloud computing on environment to solve the hazards than are arising from the releasing of carbon dioxide and also analysed several effective tools of the cloud that can lead the cloud computing environment towards "Green". Based on energy efficiency, they too designed a service model for green cloud computing which are divided in different layers, namely, End user, Green Mediator and Cloud service provider. Weixiang Jiang et.al. [30] illustrates a design of hybrid cooling architecture that helps to incorporate the thermoelectric cooler into the water cooling system for 
dealing with cooling mismatching with an efficient manner. Based on cluster traces from different technologies like Alibaba or Google and real hardware prototype they also estimate a design of hybrid water cooling that is able to minimize $58.72 \% \sim 78.43 \%$ energy consumption to control the technique of cooling mismatching. Jackson Braz Marcinichen et.al. [31] suggested a method for cooling the different parts of the system like auxiliary electronics of blade server boards, microprocessors etc. by introducing the technology of two-phase cooling cycle. This technique can execute the concept with two-phase evaporating flow in the micro evaporator cooling elements. In this paper, they proposed a simulation code which contained five different types of cases which were simulated by considering different working fluids namely HFO1234ze, HFC134a and water (for an analogous single-phase cooling cycle). In this method, different elbows and diameters of the pipes can join the elements. As per the outcome, it was presented that the liquid water cooling cycle contains 5.5 times pumping power consumption which gained from two-phase HFC134a cooling cycle and both considering a liquid pump as the driver of the fluid. In their article, X. Zhang et.al. [32] established a new model a depicts the concept which can cover the combined vertical placed servers and distributed air flow control to high the floor ventilation system. According to this paper, a simulation result can be generated as an outcome for distributed air flow control along with vertical placed server in contrast with air flow design and traditional data centre ventilation. The proposed technology explained different ventilation systems like Uneven load, Even load and Idle serve to explain that it is possible to save the cooling energy consumption consumed by traditional ventilation system with this proposed concept.

A technique, proposed by Hosein Moazamigoodarzi et.al [33] in their paper can be a solution for improving the energy savings of the Data Centres with the implementation of computational fluid dynamics that can determine the temperature distributions and characteristic airflow for several cooling architectures like row-based, room-based and rack-based. The outcome of this proposed method may be treated as important methods to cool these architectures by inform the thermodynamics models of power consumptions. The analytical result also states that the used architectures (row- and rack-based architectures) minimize 29\% (approx) coolong power and further can reduce $18 \%$ cooling power by including an enclosure within these two architectures that helps to separate cold airflow and hot airflow.

I W Kuncoro et.al. [34] defines a cooling model for increasing the efficiency and effectiveness of energy consumed by the data centres on the basis of the studies which deals with the use of dielectric fluids along with their high heat capacity. Their report helps to recognize numerous types of fluid used in the model and as per their study, the implementation of immersion cooling is much more effective to minimize the heat of the devices and also be able to serve a data centre with simple design that may rise the density of power. Jiawen $\mathrm{Yu}$ et.al. [35] defines an idea for getting the cooling and heat load index by presenting a simulation of the annual dynamic air conditioning load of buildings by using DeST(Designer's Simulation Toolkit).To evaluate the impact of energy-saving, a data centre situated in Harbin was considered as a case study. The result shown that annual cumulative cooling load may be considered as a significant and great solution for heat recovery on the basis of a comparative study between the annual cumulative heat load and annual cumulative cooling load. They also proposed a system which created use of waste heat from data rooms to help subsidiary buildings and can supply the required heat in data centres in a satisfactory manner when all the devices in data rooms in a running condition.

Carolina Koronen et.al. [36] exhibits an effective and resourceful assessment to integrate the energy system for data center through demand response and waste heat utilization with a review of EU policies related to this. For the data centres, waste heat utilization is basically a choice and is adjacent to district heating systems. The scheduling of data centre operations like temporal and spatial scheduling helps to achieve the Flexible electricity demand. As per report, in the European electricity system it may deliver more than 10 GW of demand response in the year 2030. Most of the data centres also contain supporting power systems using stand-by diesel generators and batteries that may potentially be used in power system balancing. In this paper, the authors tried to present the capability and of importance demand response and energy system integration that becomes a great method for changing the taxation and electricity market design and also develop the future policies, policy coordination. Jianxiong Wan et.al [37] tried to present a survey report on the technique of current air flow management to betterment the effectiveness of energy and cooling. The article first revised the current measurement methodologies and various instruments that are already giving the impact on the cooling performance on the basis of the inputs of thermal measurement data and then this article depicted the techniques of air flow management for several cooling components with air flow cycle. James VanGilder et.al. [38] Developed a software tool on the computationally efficient flow network model, of the airflow in ceiling-ducted containment systems to analyze the efficiency improvements afforded by the damper systems. They describe the flow network model and a closed form technique for predicting optimal damper settings to balance pod airflows. Finally the FNM can also be used in the development of damper control systems based on pressure measurement for real facilities. W. Zhang et.al. [39] presented a review report on the enabling techniques of ICT and cooling management of data centre that allows the provision to dynamically control the utilization of server and also operate the cooling devices. This paper also depicted the optimization concepts for green data centre by presenting the coupling models among the ICT and cooling management. Moreover the authers also reviewed the 
workload scheduling algorithms that designed from the optimization approaches. Ali Heydari [40] indicates the way to unpolluted the polluted air by introducing a data center system with further adding a system of misting and cooling which contains a cooling and cleaning chamber for receiving the impure air that outlets to spray the liquid droplets into the polluted air inside the cooling and cleaning chamber. After that this liquid droplets collect the particles and also eliminate a portion of the particles present in the polluted air to generate non-contaminated and pollution free air. As per the report of this paper, an airflow system can be generated from the non-contaminated air by the further addition of an airflow delivery system in the data center system. This happen due to the airflow to transmit through the servers of the electronic racks for exchanging the heat produced by servers due to their operations. Jonathan David Hay [41] highlights on the concept in which the evaporative cooling unit can be downstream from the cooling section and through the air channeling sub-system this cooling air can be channeled into a room. According to the report this air channeling sub-systems is worked in an adiabatic mode on the basis of the condition where a first set of control conditions is met. To evaporate the water into the cooling air the adiabatic mode adds the channeling cooling air through the direct evaporative cooling section. Apart from the condition of first set, if there will be a second set of control conditions then the air channeling sub-system will be worked in a hybrid mode. Through the mechanical cooling section this hybrid mode adds channeling cooling air for eliminating the heat includes channeling cooling air and also channeling the cooling air through the evaporative cooling section that helps to evaporate water into the cooling air. Robert TOZER et.al. [42] states that for cooling the data centre there is a device that includes an air conditioning unit which may supply cooled air into a cold portion of a data center. Here is a device that measure the rate of bypass airflow and this measurement can be done by segregation among the cold portion and hot portion of the data center. The bypass airflow signal can be received through a control unit from the airflow measurement device that is to yield a control signal to control the rate of the bypass airflow. According to Tracy Staedter [43] a low-power system has been developed by Forced Physics a Scottsdale, AZ., based company to reduce 90 percent energy requirements of a data centre for cooling. The company provides a passive system named JouleForce conductor for using the filtered, non-refrigerated and ambient air for whisking the heat and temperature away from computer. Leehter Yao et.al [44] emphasised on a multi-objective optimization scheme that can save the energy for the ACS (air conditioning system) of a data centre. The main objective of the proposed scheme is to increase the saved energy for AHU [air handling units] and Chillers, two most energy consuming services. Now a day, in a modern data centre, impact of cooling system is very much important and it is very difficult to generate an optimal cooling policy.

Yuanlong Li et.al [45] introduced the concept that optimizes the control policy by utilizing the huge amount of monitoring data in a modern data centre. According to the report, he authors thrown the design of cooling control policy into a problem of energy cost minimization including temperature constraints. They also tap the policy into the DRL or deep reinforcement learning, an emerging framework. Exactly, the authors offered an end-to end cooling control algorithm (CCA) which is based on the off-policy offline version of algorithm named deep deterministic policy gradient (DDPG) and on actor critic framework. In their proposed cooling control algorithm, an evaluation network is prepared to predict and determine an energy cost counter which is penalized by cooling status of the data centre room. At the time of given the current load and weather information, a policy network is also arranged for predicting the optimized control settings. Alfonso Capozzoli et.al. [46] presented an analytical report on available numerous current developed systems along with different advantages and disadvantages . It is necessary to handle carefully a several aspects of data centre like waste heat recovery, Thermal Energy Source renewable energy source. The development and improvement of energy efficiency in a data centre leads an effective and profitable growth of an industry by minimizing the operational cost and also measures higher supply of air temperature, free cooling exploitation, comprise aisles containment and optimal air distribution. A comprehensive model of data centre has been presented by

Gulnara Zhabelova et.al [47] to capture the configuration and dynamics of servers, server rooms, cooling systems (CRAH, chiller and cooling tower) and connection to the grid. The aim of this model is to assemble all elements of data centre and define the dynamics of each component for capturing the interdependencies among the components and parameters with a correct and efficient manner. The proposed model can be utilized in many studies with particular equipment to the data centre as a smart load in the power grid on the basis on effects of user action.

\section{DATA CENTRE ENERGY EFFICIENCY MEASURE}

As reported by Wikipedia [48] one of the current and effective techniques to measure the energy efficiency of a data centre is PUE (Power usage effectiveness). It is the ratio to define that how effectively a data centre can utilize the energy by the computing devices in comparison to cooling and other overhead. The ratio of PUE when it can be considered as the ideal with highest efficiency that may be utilized by IT devices. Apart from this, the PUE with the ratio 1.5 indicates the $1 \mathrm{kWh}$ energy consumption by IT devices, $1.5 \mathrm{kWh}$ by data centre and also specifies that $0.5 \mathrm{WH}$ energy may waste for the unused and unnecessary work like CPU dissipation or cooling.

There are various parameters proposed for measuring the efficiency of data centres. These are briefly described in the following Table 1: 
Table 1: Measuring the efficiency of data centres

\begin{tabular}{|c|c|c|}
\hline $\begin{array}{l}\text { Useful Metric of Green } \\
\text { Computing }\end{array}$ & Explanation & Formula \\
\hline $\begin{array}{l}\text { CUE } \\
\text { (Carbon usage } \\
\text { Effectiveness ) }\end{array}$ & $\begin{array}{l}\text { CUE is the fraction of total } \mathrm{CO}_{2} \text { discharge in } \\
\text { atmosphere by the data centre to the total energy } \\
\text { consumed by the IT devices. }\end{array}$ & $\begin{array}{l}\text { CUE }=\frac{\mathrm{TECO}_{2}}{\mathrm{TEIT}} \\
\mathrm{TECO} 2=\text { Total Emission of } \mathrm{Co}_{2} \\
\text { TEIT }=\text { Total Energy consumed by IT devices. }\end{array}$ \\
\hline $\begin{array}{l}\text { WUE } \\
\text { (Water Usage } \\
\text { Effectiveness) }\end{array}$ & $\begin{array}{l}\text { WUE is a ratio of total amount of water required } \\
\text { annually by data centres and servers for cooling } \\
\text { purpose to energy consumed by the IT devices. }\end{array}$ & $\begin{array}{l}\text { WUE }=\frac{\text { TWCA }}{\text { TEIT }} \\
\text { TWCA }=\text { Total Water consumption Annually } \\
\text { TEIT }=\text { Total Energy consumed by IT devices }\end{array}$ \\
\hline $\begin{array}{l}\text { ERE } \\
\text { (Energy Reuse } \\
\text { Effectiveness) }\end{array}$ & $\begin{array}{l}\text { ERE is a fraction of Profit of reuse energy of Data } \\
\text { centre by total energy consumed by IT devices. }\end{array}$ & $\begin{array}{l}\mathrm{ERE}=\mathrm{TE}-\mathrm{RE} \\
\text { TEIT } \\
\mathrm{TE}=\text { Total Energy, RE }=\text { Reuse Energy } \\
\mathrm{TEIT}=\text { Total energy consumed by IT devices. }\end{array}$ \\
\hline $\begin{array}{l}\text { ERF } \\
\text { (Energy Reuse Factor) }\end{array}$ & $\begin{array}{l}\text { ERF measures how much energy like renewable } \\
\text { energy sources etc. is reused by distributing by the } \\
\text { outside of data centres operational process. }\end{array}$ & $\mathrm{ERF}=\frac{\text { Energy reused by data centres }}{\text { Total IT devices power }}$ \\
\hline $\begin{array}{l}\text { DCP } \\
\text { Data Centre Productivity }\end{array}$ & $\begin{array}{l}\text { DCP determines the complete valuable work } \\
\text { performed by the Data Centre by the Total } \\
\text { resources required to complete the task. }\end{array}$ & $\mathrm{DCP}=\frac{\text { Total completed valuable work }}{\text { Total IT resources }}$ \\
\hline $\begin{array}{l}\text { CPE } \\
\text { Compute Power } \\
\text { Efficiency }\end{array}$ & $\begin{array}{l}\text { It calculates the total amount of power is utilized } \\
\text { for computing. }\end{array}$ & $\begin{array}{l}\text { CPE }=\frac{\text { Complete IT devices utilization }}{\text { PUE }} \\
\text { Complete IT devices } \quad \text { utilization x TEIT } \\
\text { Total Power of Server or Data Centre }\end{array}$ \\
\hline
\end{tabular}

In this paper we list some data centre energy efficiency techniques with problem definition described in some papers along with the solution.

Table 2: Green cloud computing techniques

\begin{tabular}{|l|l|l|}
\hline $\begin{array}{c}\text { Green cloud } \\
\text { computing } \\
\text { techniques }\end{array}$ & \multicolumn{1}{|c|}{ Problem Definition } & \multicolumn{1}{c|}{ Solution } \\
\hline $\begin{array}{l}\text { Liang Hu and Jia } \\
\text { Zhao, Gaochao } \\
\text { Xu [49] }\end{array}$ & $\begin{array}{l}\text { Reduce Power Consumption and } \\
\text { increase Energy Efficiency. }\end{array}$ & $\begin{array}{l}\text { They stressed and revised on various existing techniques namely } \\
\text { Dynamic Component deactivation, DVFS (Dynamic voltage } \\
\text { frequency scaling), ACPI (Advanced Configure } \\
\text { and Power Interface), Heterogeneous server clustering, pMapper } \\
\text { architecture to reduce the rate of energy consumption. }\end{array}$ \\
\hline $\begin{array}{l}\text { Chowdhury, } \\
\text { Chatterjee } \\
\text { al.,[50] }\end{array}$ & $\begin{array}{l}\text { How to analysed energy consumption } \\
\text { of cloud computing of different } \\
\text { organizations. }\end{array}$ & $\begin{array}{l}\text { In this article the authors emphasised on several methods like } \\
\text { resource virtualization to reduce the energy consumption rate of } \\
\text { cloud computing for introducing the way to diminish the carbon } \\
\text { footprint. }\end{array}$ \\
\hline $\begin{array}{l}\text { Rahul Yadav et } \\
\text { al [51] }\end{array}$ & $\begin{array}{l}\text { Focuced on the problems that shows } \\
\text { the violation in cloud environment } \\
\text { due to enormous amount of energy } \\
\text { consumption and service level } \\
\text { agreements (SLAs).. }\end{array}$ & $\begin{array}{l}\text { This paper presented the adaptive heuristic algorithms to minimize } \\
\text { CDC energy consumption along with minimal SLA. In this paper, } \\
\text { they emphasised on the algorithms like least medial square } \\
\text { regression for overloaded host detection and minimum utilization } \\
\text { prediction for VM selection from overloaded hosts. }\end{array}$ \\
\hline
\end{tabular}




\begin{tabular}{|c|c|c|}
\hline $\begin{array}{lr}\text { Shilpi } & \text { Saxena } \\
\text { and } & \text { Deepika } \\
\text { Saxena }[52]\end{array}$ & $\begin{array}{l}\text { Stressed on the method to diminish } \\
\text { the enormous volume of electrical } \\
\text { energy consumed by the Data centres } \\
\text { which delivers services and leads a } \\
\text { danger towards environment by } \\
\text { increasing the carbon emissions and } \\
\text { also the impose of high operational } \\
\text { cost. }\end{array}$ & $\begin{array}{l}\text { They offered a green cloud computing architecture with the } \\
\text { approach of energy-aware to deliver the data centre resources to } \\
\text { client applications with an effective approach that develop the } \\
\text { energy efficiency of the data centre, at the time of delivering the } \\
\text { exchanged QoS (Quality of Service). }\end{array}$ \\
\hline $\begin{array}{l}\text { Carrega, } \quad \text { A.; } \\
\text { Repetto, M.[53] }\end{array}$ & $\begin{array}{l}\text { How to improve the program } \\
\text { efficiency, less storage space and high } \\
\text { performance and grid computing by } \\
\text { using the software technique. }\end{array}$ & $\begin{array}{l}\text { In this paper the authors suggested an algorithm with a novel } \\
\text { consolidation approach to exploit rising the software development } \\
\text { paradigms. }\end{array}$ \\
\hline $\begin{array}{l}\text { Procaccianti, G.; } \\
\text { Lago, P.; Bevini, } \\
\text { S.[54] }\end{array}$ & $\begin{array}{l}\text { How to improve the computing } \\
\text { efficiency of the servers }\end{array}$ & $\begin{array}{l}\text { They presented an approach that examines the type of software } \\
\text { architectures for cloud service provisioning which allows to reach } \\
\text { the energy-efficient solutions by establishing the preliminary } \\
\text { results of a systematic literature review. }\end{array}$ \\
\hline $\begin{array}{l}\text { Pahlevan et al. } \\
\text { [55] }\end{array}$ & $\begin{array}{l}\text { How to manage the Green data } \\
\text { centres and reduce the energy and } \\
\text { cost. }\end{array}$ & $\begin{array}{l}\text { They presented an optimization framework for managing green } \\
\text { data centres using multilevel energy reduction techniques jointly. } \\
\text { The results obtained demonstrate satisfactory results as there is } \\
\text { considerable, up to } 96 \% \text { savings in electricity bill. }\end{array}$ \\
\hline Sharma [12] & $\begin{array}{l}\text { Focused on the problem that how } \\
\text { computer programs can be utilized in } \\
\text { an effective and efficient manner by } \\
\text { using all the existing cores of CPU for } \\
\text { saving the energy. }\end{array}$ & $\begin{array}{l}\text { It stresses on the comparative case studies for making a } \\
\text { comparison the responsibilities of single-core version and } \\
\text { multi-core version of a insignificant problem of adding the required } \\
\text { numbers stored in an array. } \\
\text { The approach of the paper helps to expose that the multicore } \\
\text { approach delivers improved performance with more number of } \\
\text { computation, else it shows poor performance than the trivial } \\
\text { single-core method. }\end{array}$ \\
\hline More et al. [14] & $\begin{array}{l}\text { How to use the virtualization } \\
\text { technique and how to reduce the } \\
\text { power utilization. }\end{array}$ & $\begin{array}{l}\text { This paper try to focus on several models and algorithms that may } \\
\text { impact on development of green cloud computing by following the } \\
\text { virtualization process which mainly deals with VMs(virtual } \\
\text { machines) consolidation. According to this paper, by the concept of } \\
\text { deactivating and reactivating of physical devices the power } \\
\text { consumption can be reduced to meet current workload. }\end{array}$ \\
\hline $\begin{array}{l}\text { Mesaad et al. } \\
{[16]}\end{array}$ & $\begin{array}{l}\text { How to manage e- waste and reduce } \\
\text { energy consumption. }\end{array}$ & $\begin{array}{l}\text { They provide an analysis of the current green computing initiatives } \\
\text { and an overall comparison between them to show their efficiency. } \\
\text { They introduce HP program is the greenest computing } \\
\text { waste-management initiatives from the point of e-waste } \\
\text { management. Considering Energy consumption, the Energy Star } \\
\text { and EPEAT initiatives happen to be the most successful program } \\
\text { based on the latest energy savings statistics and their users trusted } \\
\text { labelling. }\end{array}$ \\
\hline Shaikh et al. [56] & How to move towards a green IOT & $\begin{array}{l}\text { In this paper, the authors emphasised on a review study of different } \\
\text { applications related to IoT, several projects and relevant efforts } \\
\text { happening currently with some new challenges which may lead an } \\
\text { effective and efficient green IoT in near future. }\end{array}$ \\
\hline $\begin{array}{l}\text { Sharma et al. } \\
\text { [57] }\end{array}$ & $\begin{array}{l}\text { How to describe the green university } \\
\text { data centre. }\end{array}$ & $\begin{array}{l}\text { They made an analysis and describes a green university data centre } \\
\text { and in the process makes an excellent insight into the various } \\
\text { operational and competency characteristics. }\end{array}$ \\
\hline Sofia et al. [58] & $\begin{array}{l}\text { How to reduce the cost of hardware } \\
\text { and manage the voltage and } \\
\text { frequency of the processor. }\end{array}$ & $\begin{array}{l}\text { This article projects on the technique named DVFS (Dynamic } \\
\text { Voltage Frequency Scaling) that deals to manage the voltage and } \\
\text { the frequency of the processor without damaging the performance. } \\
\text { Favourable results are obtained by implementing GTS along with } \\
\text { DVFS in cloud computing environment. }\end{array}$ \\
\hline
\end{tabular}




\begin{tabular}{|c|c|c|}
\hline $\begin{array}{l}\text { Walter } \begin{array}{l}\text { Binder, } \\
\text { Niranjan } \\
{[26]}\end{array} \\
\text { Suri }\end{array}$ & $\begin{array}{l}\text { How to diminish the rate of energy } \\
\text { consumed by the data centre. }\end{array}$ & $\begin{array}{l}\text { According to this paper, their proposed method can be a reason to } \\
\text { minimize the energy consumption in data centres. Their proposed } \\
\text { approach offers an idea that can preserve the energy by } \\
\text { consolidating services dynamically on a subset of accessible servers } \\
\text { and closing that servers for a time being. The authors designed their } \\
\text { proposed work on an algorithm with probabilistic service dispatch } \\
\text { with the purpose to reduce the number of running servers so that the } \\
\text { servers can serve the better quality service required by service-level } \\
\text { agreements. The proposed approach ensures to make an positive } \\
\text { impact on energy consumption process by delivering the estimated } \\
\text { energy consumption and projected growth in data centres [59]. }\end{array}$ \\
\hline $\begin{array}{l}\text { Fumiko Satoh } \\
\text { et,al [60] }\end{array}$ & $\begin{array}{l}\text { How to properly utilize the energy } \\
\text { consumption and reduce carbon } \\
\text { emission. }\end{array}$ & $\begin{array}{l}\text { They established a proposal to reduce the energy consumption rate } \\
\text { at various data centres by introducing a cloud energy management } \\
\text { systems with sensor management function along with an optimized } \\
\text { VM allocation tool. }\end{array}$ \\
\hline $\begin{array}{l}\text { Towards } \\
\text { Greener Services } \\
\text { in Cloud } \\
\text { Computing: } \\
\text { Re-search and } \\
\text { Future } \\
\text { Directives. } \\
\text { Soha Rawas, } \\
\text { Wassim Itani, et, } \\
\text { al[29] }\end{array}$ & $\begin{array}{l}\text { How to rise the energy efficiency and } \\
\text { effectiveness in servers by } \\
\text { minimizing the electricity bills and } \\
\text { toxic effects of carbon footprints on } \\
\text { environment.. }\end{array}$ & $\begin{array}{l}\text { This paper illustrates different elements which forms the platform } \\
\text { of the cloud computing. It plays an significant role in the } \\
\text { consumption of total energy and also the direction to research work } \\
\text { for establishing a green cloud environment. In this paper the author } \\
\text { proposed an effective green cloud architecture to deliver an } \\
\text { effective and integrated solution for the cloud providers which } \\
\text { allows to use the computer resources in an energy efficient manner. }\end{array}$ \\
\hline
\end{tabular}

Different cooling techniques used in Data Centres:

Several effective approaches have been developed through different techniques to cool the data centres that are depicted through the following figure:

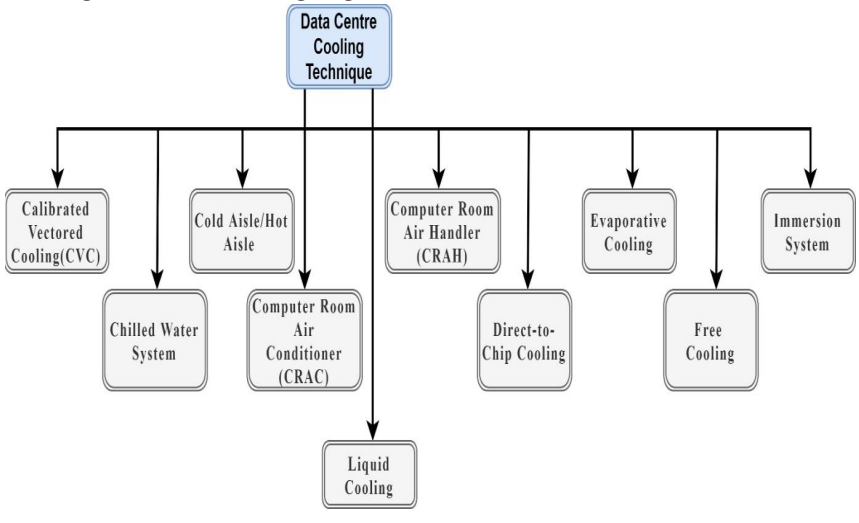

Figure 1: Different Data Centre Cooling Techniques According to [9] Calibrated Vectored Cooling (CVC) is used by the high density servers for their cooling technology. To manage the heat more efficiently it allows the cooling system to elevate the airflow path through equipment. As per the report presented by techopedia [63], an air cooling and conditioning technology named CVC (calibrated vectored cooling) can be utilized to exhaust heat by allowing the cool air in the server the surroundings along with several devices.

It was designed by IBM for implementation and use with the blade server series and other products in very close proximity to a number of computing equipment. CVC improves and optimizes the flow of cool air in computers and server systems. It is implemented in blade server systems in a small enclosure/chassis with a high number and density of processors, motherboards and other circuit boards.

Being a highly component-dense system, such devices and equipment produce a large amount of heat. CVC works here by passing cool (refrigerated) air into the hottest part of such systems, not only enabling lowered device temperatures but also limiting the required number of internal cooling fans. The chilled water system is the technique that allows a system in which a chiller plant which is present in the system that provides the water. The data centre utilizes this chilled water for cooling the air which brings by the computer room handlers.

According to the design developed by Tony Evans [64], illustrates the concept of CRAH also called Computer Room Air Handlers combined with a chiller. This combination is also called chilled water system in which the working components of the refrigeration cycle are displaced and relocated from the computer room air conditioning systems to the device known as a water chiller. 


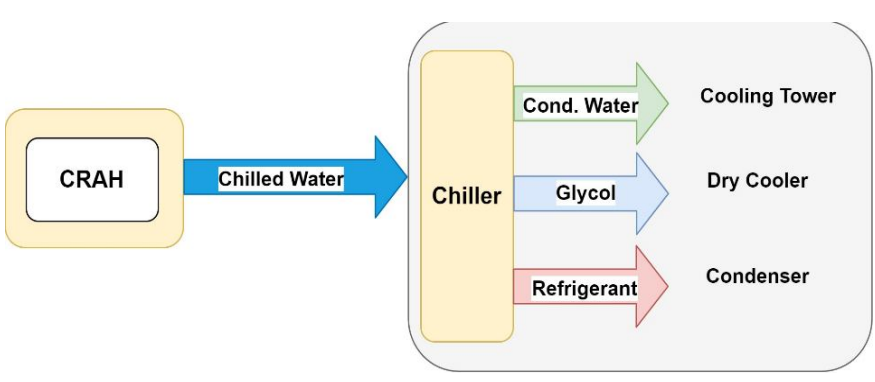

Figure 2: Chilled Water System

As per the concept, the chiller makes chilled water which is shifted to CRAH units that situated in IT environment, from the chiller via the method of pumping in pipes. The concept of CRAH is different in respect of its working flow where although it looks alike to the computer room air conditioners. The working flow of CRAH deals with the approach where this air handlers remove the heat for cooling the air by throwing the hot air present in computer room. The removing of warm air done by the chilled water coils which is occupied by circulating chilled water and this removed heat from IT platform, moves with the chilled water leaving the CRAH and then also returns to chiller where the chillers eliminates the heat from the warmer chilled water for transferring this heat to condenser water that is an alternative stream of circulating water that flows via the machine known as cooling tower. The technique of Cold Aisle/Hot Aisle introduces the approach for distributing the server rack of the data centre which are using the rows of "cold aisles" and the "hot aisles" in an alternative manner. This method presents the feature where the cold aisles consume on the inner part of racks and the hot aisles which are containing the hot air that evacuates on the rear part of the racks. In this system the hot aisles eject warm air into the system with air conditioning for cooling and after that it emitted to cold aisles. To avoid the extreme heat and loss of chilled air, the blank racks occupy the blanking panels. In a data centre the CRAC units are alike to traditional air conditioning systems with a compressor to draw the air through a cooling unit along with refrigerant. In the view of the usage of energy, this system is not so much effective and efficient although the equipment itself is inexpensive.

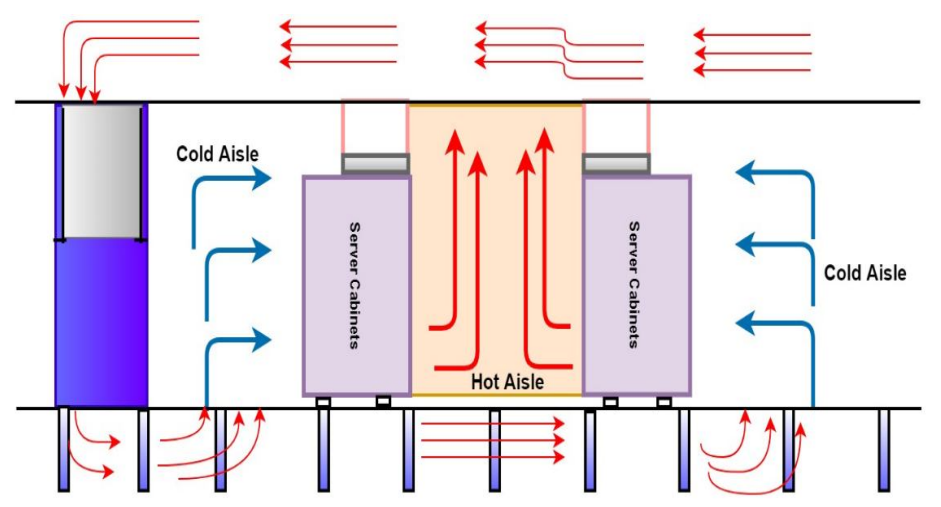

Figure 3: Cold Aisel/Hot Aisel
In the CRAH system the function of CRAH unit works as the semi system of the larger system linking with a chiller anywhere of the facility. Inside the unit, the cooling water flows over a chilled coil within the unit for drawing the air from the outside by using the modulating fans. With the use of this technology, the units of CRAH shows much more efficiency when they used in the location with cold annual temperatures.

The data centre liquid cooling technique of Direct-to-Chip Cooling allows a system where the pipes are used to provide the coolant towards a cold plate and this cold plate diffuse the heat by combined with processors in the motherboard. The removed heat is served into a chilled-water loop and gathered in a chiller plant. This server cooling technique is considered as one of the efficient techniques due to its power to cool the processor directly. One of the most important challenges is the fall of data centre power consumption. The concept of recycling and reusing of waste heat is considered as very necessary and focused area when arises the concept to develop a sustainable and energy efficient data centres. These two subjects are related to each other through the direct-to-chip liquid cooling or the liquid cooling of server racks as both of these two subjects are the combined solution that helps to transmit an important amount of the excess of heat energy back for a cost-effective usage. Apart from this facility of reusing the waste heat, another facility that it may serve is the remarkable decreases of the rate of the consumption of power which is used for cooling fans and related with the rack-level cooling systems and the server blades. The water evaporation and consequent removal of heat from out of the air can be accomplished by the evaporation of cooling that controls the heat by exposing the warm air into water. A misting method or the wet particles like mat or filter can be the form of generated water. As the system doesn't follow the CRAH units and it needs a huge amount of water so it is considered as a very effective method for making the system more energy efficient. The data centre cooling towers plays an important role to evaporate and also transfer the extra heat to the outside atmosphere.

The data centre liquid cooling technique of Direct-to-Chip Cooling allows a system where the pipes are used to provide the coolant towards a cold plate and this cold plate diffuse the heat by combined with processors in the motherboard. The removed heat is served into a chilled-water loop and gathered in a chiller plant. This server cooling technique is considered as one of the efficient techniques due to its power to cool the processor directly. One of the most important challenge is the fall of data centre power consumption. The concept of recycling and reusing of waste heat is considered as very necessary and focused area when arises the concept to develop a sustainable and energy efficient data centres. These two subjects are related to each 
other through the direct-to-chip liquid cooling or the liquid cooling of server racks as both of these two subjects are the combined solution that helps to transmit an important amount of the excess of heat energy back for a cost-effective usage. Apart from this facility of reusing the waste heat, another facility that it may serve is the remarkable decreases of the rate of the consumption of power which is used for cooling fans and related with the rack-level cooling systems and the server blades. The water evaporation and consequent removal of heat from out of the air can be accomplished by the evaporation of cooling that controls the heat by exposing the warm air into water. A misting method or the wet particles like mat or filter can be the form of generated water. As the system doesn't follow the CRAH units and it needs a huge amount of water so it is considered as a very effective method for making the system more energy efficient. The data centre cooling towers plays an important role to evaporate and also transfer the extra heat to the outside atmosphere.

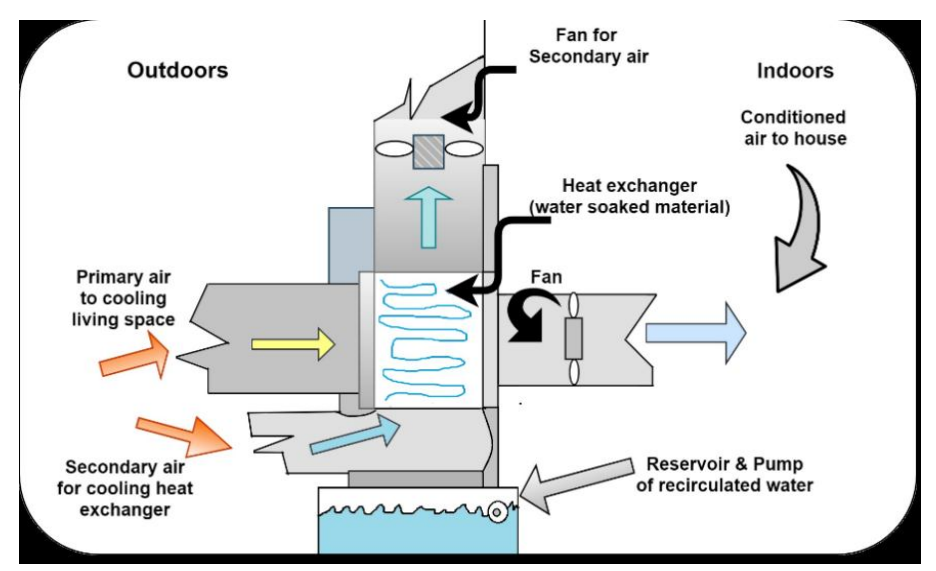

Figure 4: Direct/Indirect Evaporative Cooling

In certain climates, to implement an energy efficient and effective method to chill the server of a data centre, the system avoid the technique of using cooling the same water continuously and follow the method where the outside atmosphere can be used for generating the chilled air within the servers.

Yin Zhang et. al. [65] presented the report that in a data centre, $40 \%$ (aprox) of total electricity can be consumed by the centre.

According to this paper, the technique of the system of free cooling is considered another attractive and promising effective technology for minimizing the ratio of the loading power of electrical chiller. It also can reduce the energy consumption power for cooling by utilizing the natural sources of free cooling. In [65], the authors presented a comparative study of four types of free cooling system on the parameters like the effects of the energy savings, techniques etc. Type 1: the direct fresh air cooling is very much effective as it is considered as the highest free cooling potential but in this system, it is difficult to get the indoor air's quality due to the mixing of the indoor-outdoor air. Type 2: the rotating wheel heat exchanger is another type, in which there is a different route for indoor airflow and outdoor airflow for heat exchange purpose . For the indirect free cooling, this type of system can be implemented in indirect free cooling as under the similar climatic circumstances, the efficiency of PUE certainly rise. Type 3 : The combination of rack back plate and heat pipe can raise the rate of heat transfer along with free cooling system and also develop the efficiency of cooling technique by 3-5 times in contrast with the traditional heat exchangers. Type 4: the water-based free cooling system leads the working mechanism with three different modes depending on the several outdoor temperatures by incorporating a heat exchanger along with electrical chiller. Power Usage Effectiveness (PEU) can be reduced by raising the load ratio of free cooling that may save the usage of electricity. For practical application, in a data centre, the cooling system design depends on different parameters like local climatic conditions, indoor air quality requirement, room space, saving demands, capital investment and operation costs.

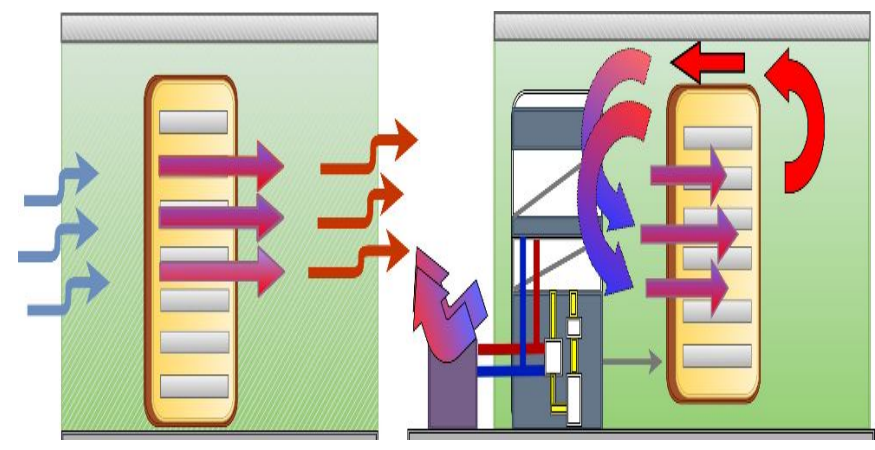

Figure 5: Direct/Indirect Free Cooling

The Immersion System is an approach to deals with an advance solution of data centre on the method of liquid cooling in which the hardware based equipment submerges into a bath of liquid where this liquid is the kind of dielectric fluid with non-flammable and non-conductive characteristics. As reported by gigabyte.com [66], the Immersion Cooling is a new approach of cooling technology for the data centres where for a two-phase immersion system of cooling, in contrast with the other heat conductor like water, oil or air, the dielectric liquid is considered much more better option for transferring heat. This cooling technology generates more clear, non-flammable and eco-friendly liquids. It is not required to use the pumps and jets to keep hardware cool. Without losing the extra energy, the circulation occurs passively by the natural process of evaporation. The elimination of conventional cooling hardware leads a better and efficient cooling. This passive process utilizes lower energy in comparison to traditional air, 
water or oil cooling.

The Liquid Cooling method deals with the concept where the cooling technology tries to take away the heat from the air by using liquid. Airflow in one of the popular method to eliminate heat from the chassis of the servers and other equipment. According to Tony day et.al. [61] , for typical servers, the CPU is the responsible for almost $70-80 \%$ of the heat generation and the remaining heat from different devices and peripherals like hard drives, memory, power supply, SSD, hard drives, etc. Maximum uses of graphics processing unit (GPU) can lead the increasing of heat generation within the IT chassis and as per report a GPU is capable to produce over 400 As the liquids re containing the $r$ capacity to capture heat by unit volume so that it helps the cooling technologies to eliminate heat more effectively and also rise the clock speed very efficiently. Moreover the heat is rejected through dry cooler to the atmosphere or through cooling towers in case of hotter environments. Kevin Heslin [62] reported that the liquid brings and absorb heat effectively from ITE than air. Heat sink is contacted with liquid that flows via a server and also contact with a heat sink within the equipment for removing the heat from ITE by absorbing the heat. ITE components are immersed within a liquid with non-conductive characteristic which absorb the heat for transferring it away from the components. The authors also reported in this paper that there are two primary types of liquid cooling namely, conductive or cold plate (direct to chip) and immersive.

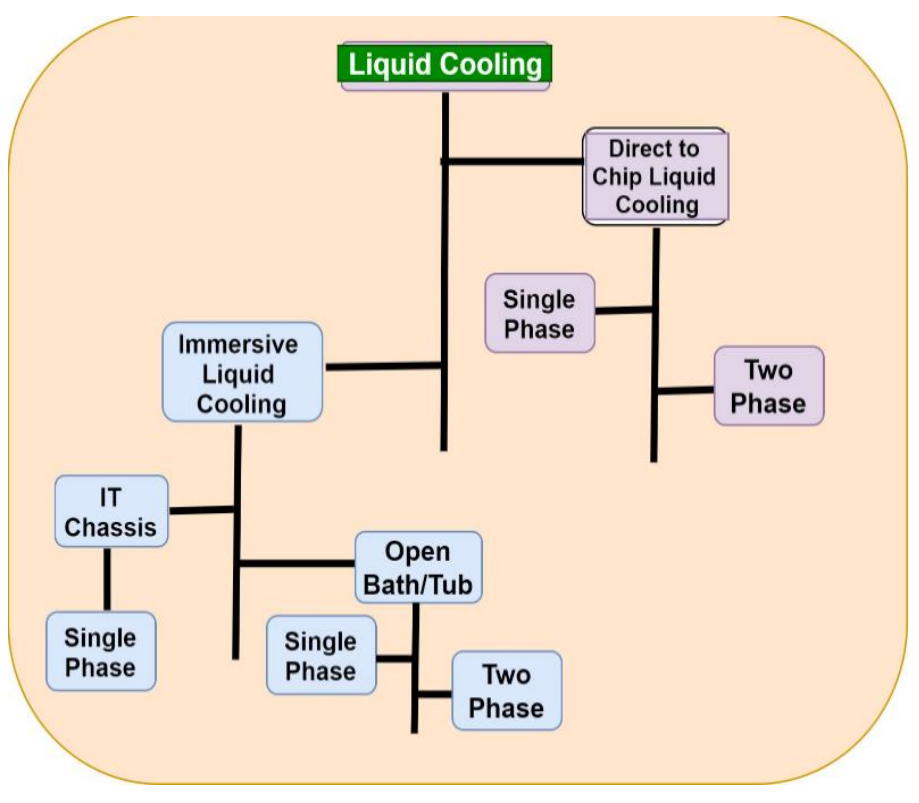

Figure 6: Liquid Cooling Techniques

Comparison and detailed study of different cooling systems: Required electrical power is one of the reasons to rise the heat in a data centre that may be removed by implementation of a suitable cooling system. As per reported by Alfonso Capozzoli et.al. [66], to get reliable high energy with low cost, there should be appropriate and well-designed cooling solution as per design criteria which may hide the worst case scenario in a cooling even though most of the servers usually work with quite lower capacity which is less than $100 \%$. In cooling design system, the control and increasing the assumption of temperature plays an important role during a utility power outage. The Air-cooled system is the main support of a data centre which are developing over the years for coping the advance in the IT equipment. In order to manage the increasing power densities gradually in the data centre, the evolution of air-cooled system is proceeding to localize the units of cooling system and physical partitioning of the airstream. On the other side, for cooling high power density data centres, the liquid-cooled systems are flourishing as the most efficient, developing and capable solving techniques. But on the basis of rapid and enormous growing of the IT industry, the techniques of air-cooled systems might be failed to fulfill the cooling process. Various mechanical equipment is providing a mass cooling capacity due to the use of different air cooled systems like the direct expansion or direct expansion glyco and chilled water systems,. In a data centre industry, the method of heat rejection is considered as the ending step in a technique for removing the heat where the most common heat rejection systems are cooling towers and dry coolers. It is very much important and effective to use an economizer mode in data centres to accomplish the energy in an efficient developed and effective manner along with the way for saving the energy. In a data centre, the cooling plant is composed of a dynamic mechanical device and a heat removing system where this mechanical device can be a chiller or a direct expansion system and in this system this mechanical devices is also incorporated with the terminal cooling devices. In this technique, the or direct expansion system contains a CRAC and a heat removal system like air-cooled condenser Although it is considered as a simple and easy solution to maintain with less capital cost but in this method, each CRAC required a condenser and the piping system with short length which is considered the main drawback of this technique. Evans T. [67] reported that this solution usually utilized by the computer room of data centre with the IT power of 7 to $200 \mathrm{~kW}$. In this regard, the glycol-cooled system is considered as an substitute solution to remove the heat by applying a mixture of glycol as a fluid for heat removal from the CRAC for drying the cooler. As per [67], the glycol piping works for a longer length with a dry cooler that allows the several CRACs in a DC from $30 \mathrm{kw}$ to $1000 \mathrm{kw}$. In a system with chilled-water solution, the chiller serves chilled water for the CRAH where the terminal device promises to control the humidity and IT temperature only. The heat rejection technique may vary upon the different chiller type like air-cooled, glycol-cooled or water-cooled. As per report, an efficient chilled-water system increases the capability of a data centre even though this system contains 
huge cost for a data centre with the IT power of lesser than $100 \mathrm{~kW}$ and needed for the installation of IT power more than $200 \mathrm{~kW}$.

Within Air-Cooled systems, the air along with the ability of cooling and proper distribution capability should be delivered by the terminal cooling peripherals. In their paper, Schmidt RR et.al. [68] focused on different parameters which may impact on the cooling efficiency like ceiling height, in which a layers of hot air may arise that upraised the floor ceiling height and it is significant for getting a proper distribution of air among the IT devices and the direction of the flow of the air within the room. Capozzoli A et.al. [69] highlighted on two main problem of air distribution within data centre mainly, the avoiding of cold air and the recirculation of the air. The by-pass of cold air may arise if there is a leakage or any high rate of flow over the cold air path. Capozzoli A et.al. [70] stated that it may occur that the cold air stream can avoid and may skip from the supply of cold air towards the exhaust air without affecting on cooling technique. According to [71], the poor and inefficient air management technique serves a cooling system with less efficiency which leads the growing of local heat and temperature along with a malicious and bad cycle. According to [72], a single rack within ten works along with temperature which is much more than standard recommendations and the maximum hot spots arise within the data centres with light load that specifies the poor air management as the reason of hot spots.

Niemann J et.al. [73] reported that generally it is desirable for a data centre to set the temperature for cooling system less than the requirements that needed by the IT platform to avoid the hot spot. The attachment of active aisles containment is considered as the primary step to increase the betterment. Apart from this, for a data centre, one of the most efficient, effective and low cost technique is the hot or cold containment aisles for the betterment energy efficiency in a data centre in which the containment can maximize the cooling efficiency by allowing the physical partitioning of the of the air stream for which the problems of recirculation can be bypassed which can supply air at higher temperature According to analysis of this paper, the hot aisle containment can be treated as the best solution in comparison to the containment of cold aisle. It helps to reach an improved and better air flow distribution by easily focus on the devices of terminal cooling that are nearer to the source.

This system also helps to categorize the cooling system into the air-cooled, Room based, In-row based and Rack based cooling. The room cooling, row cooling or rack cooling solutions are categorized by several techniques of distributing the air even though they all contain the equal quantity of capacity for cooling and also are categorized by different cooling efficiency with capital cost. Among the all, the cooling systems of in-row based and rack-based are gaining the benefit of an airflow path which is smaller and permitting a decreasing of the necessity of the fan power that helps to rise the efficiency. The above mentioned various solutions may allow several power densities like the cooling systems on rack-based to help the power density of $50 \mathrm{~kW}$ per rack [16]. Apart from this, due to the large amount of the units for cooling and piping, the solutions with rack-based and In-row cooling offers maximum costs as capital in contrast with the room cooling solution. To accomplish the in-row cooling solution, it is needed to place the terminal cooling equipment in between the racks or overhead. There are two different design namely closed or open are present in the rack-based cooling solution. Regarding this closed design, Dunlap K et al. [74], represented in his paper that due to the position of the servers and the end cooling peripherals of closed design system inside the closed rack envelope, the airflow is totally isolated from the data centres. On the contrary, in case of open design, Almoli et. al. [75] stated that for cooling the IT devices it share with a room-based solution by a rear door heat exchanger. The real door depends on fans for its active and passive states as the rear door considered as active when it contains the fans which are dedicated and also able to control the airflow via the back door heat exchanger. On the other hand, the rear door considered as passive when via rear door, the system servers fan drive the airflow. The present data centres can utilize these solutions which permits to use the racks with high density for separating them from the cooling system on the basis of room- based technology. On the other hand, the in-row cooling solution is suggested for the present data centres which permits to use the server racks with high density that will be $5 \mathrm{~kW}$ or above per rack whereas the rack-based cooling solution is recommended for the present data centres which permits to use the racks with high density . According to Chi YQ et al. [76], main benefit is the ability of heat transfer in an huge amount in per unit that permits to accomplish the required task with lower temperature variance in between the coolant and CPU. Furthermore, this solution removes two less effective and efficiency steps and these are eat-sink-to-air heat transfer and air-to-coolant heat transfer. As per the report of [77], direct liquid-cooled system is considered as another developing liquid cooling technique. In this system, the server which is closed and containing a fluoro-organic dielectric coolant that is in direct contact with electronics for transferring the heat towards a water jacket through the natural convection and finally this heat can be moved to an external loop from the cabinet that ultimately released or reused. As reported by Zhang $\mathrm{H}$ et al. [78] , the free cooling system, which is the utilization and usage of cooling system in an economizer mode, considered as an emerging solution for gaining energy saving which allows the usage of the outside climate in a favorable condition for cooling process through the partial load work or by-pass load work of the mechanical active component for minimizing the energy to save the cost. In an economizer mode of data centre, 
the position of geographical site plays an important role for effective and efficiency matter. From the two free cooling types, namely air-side free cooling and water-side free cooling, the air-side free cooling can be direct or indirect within the data centre which acts on the air in a direct mode. To get the direct free-cooling, the cold air can be puffed directly the outside into the data centre if the outside conditions will be fulfilled by particular conditions. Although the direct air-side free cooling is effective and simple but direct air-side free cooling can generate humidity, particulates and gaseous contaminants in indoor environment which can effects on the IT reliability. On the contrary, an air-to-air heat exchanger can be implemented by indirect air-side free cooling to avoid contamination. In a few circumstances, an evaporative cooling process can be utilized to rise the differences of temperatures among the two air streams. According to the paper, $40 \%$ of the total number of data centers has been adopted by direct air-side economizer by implementing the free cooling technologies. The social sites like Facebook and Yahoo are avoiding the usage of chillers to deliver their services with advanced air-side economizer based cooling system which is able to operate $90 \%$ of time in economizer mode. To maximize the heat dissipation density, the DC applications will contain huge number of transistor for chip and clock rates following Moore's law. In contrast with the sensible heat of a single-phase fluid the nucleate boiling can be the reason to rise convection heat transfer coefficient by using the latent heat.

As reported by [79], for data centre cooling, evaporative cooling solutions are comparatively new although this system have been used in residential settings for years in place of traditional air conditioning with refrigerants. In case of a hot data centre where humidity is already carefully monitored to avoid damaging sensitive electronics there the said system is very much suitable for low-humidity environments with a high temperature and a consistent water supply. The system of evaporating cooling is considered as a substitute to air conditioners that use refrigerant that can contribute to ozone depletion and for operation it also need more energy. To cool a place, the evaporating cooling system relies on the natural evaporation of water by drawing air across wet filters or pads. The water absorbs the heat in an efficient manner and the cool air is left and redistributed into the space. Damena Agonafer, Damena Agonafer, assistant professor of mechanical engineering at Washington University in St. Louis proposed a unique evaporative cooling system that is considered as the first evaporative cooling solution to use a porous membrane with microscopic pillars. In his design, as the membrane retains refrigerant which is a key component of the system, so water can't be used safely in electrical applications which ultimately removes heat faster than a traditional evaporative cooling system. Ebrahimi K et al. [80] focused on the further improvement of energy efficiency along with the concept of reducing the energy consumption of data centre by introducing the reuse of waste heat produced through the IT devices as it is containing an vital aspect to reduce the fatal effects of $\mathrm{CO} 2$ emissions in data centres. Another vital step to reduce the serious effects of $\mathrm{CO} 2$ emissions in data centre industry is the incorporation of Renewable energy sources and Thermal energy storage through the development of RES (Renewable Energy Sources) which has a great impact on total energy consumption of data centre. The intermittent nature of RES is the main barrier of this concept whereas every day the data centre need energy for 24 hour.

\subsection{Free Cooling System}

The process of Free Cooling technique deals with the concept of minimizing the rate of consumption of the power of the air conditioning system in a site by consuming the essential and required amount of power but without hampering on availability with its reliability.

\section{Direct Free Cooling System}

It can be defined by some techniques, namely, open the window then blow the cold air from outside over the Data Centre, next collect the hot air and transport it back. Basically in this theoretical and physical method, only the procedure of "moving the air" needs energy. In practical scenario, there is a lot of complexity as in a data centre, the IT device is not always in a favorable and comfortable condition due to the uncomfortable condition of outdoor air which appears in several forms in several time like cold, hot, dry or in humid condition. It is not always clean rather it is often full of particles that can be very hostile to modern IT equipment. Therefore the direct free cooling should only be used in the situation where the negative properties of the outdoor air can be controlled by financially acceptable measures. The outdoor air should be filtered an expensive process, before it allowed access to the data centre.

In case of too cold, a certain proportion of warm air from data centre is needed to mixed with that cold water to control and moderate the air into the IT equipment. It is required to design the concept of airflow and the control system in the data centre for ensuring this supplementary mechanical cooling will be required in the situation when the outdoor air is too warm. Therefore the direct free cooling may not be a reasonable and suitable option in the places where average annual temperatures is very high.

However air humidity is another challenge. Besides this, in some situations, the law does not allows the concept of the usage of Direct Free Cooling due to the wide openings of outer walls of the structure which may danger for the safety and security purpose. Therefore sometimes it is needed that the key advantages should put into perspective when an costly and extra measures are required if there is any conditions arises in the site. 


\subsection{Indirect Free Cooling}

In this system the window stays closed that can be an obstruct to the outside air with all its unwanted and bad features for entering in Data Centre and has to stay the outside of data centre. All of this said potential difficulties with the method of Direct Free Cooling are not found in the method of Indirect Free Cooling. In spite of all the above mentioned disadvantages of Direct Free Cooling, it is much more capable over the system of Direct Free Cooling as always there must be one heat transfer for taking place in between the air inside the Data Centre and the outside air.

A list of differences of the different parameter wise differences between liquid cooling with Air flow cooling systems [62].

Table 3: Different parameter wise differences between liquid cooling with Air flow cooling systems

\begin{tabular}{|c|c|c|c|}
\hline Sl. No. & Parameters used & Air Flow System & Liquid Cooling System \\
\hline 1. & Capital Cost & One time investment is high. & $\begin{array}{l}\text { High, as it carry water to each rack for } \\
\text { distributing it to the server. This system } \\
\text { can minimize the traditional cooling } \\
\text { system cost by removing } 80-95 \% \\
\text { amount of heat. }\end{array}$ \\
\hline 2. & Energy Cost & Higher & $\begin{array}{l}\text { Lower than Air flow. It can reduce IT } \\
\text { Fan energy and decreases electric bill. }\end{array}$ \\
\hline 3. & $\begin{array}{l}\text { Rack Density } \\
\text { or } \\
\text { Compaction }\end{array}$ & $\begin{array}{l}\text { It is possible to continue the air } \\
\text { cooling system usually with more } \\
\text { than } 20 \mathrm{~kW} / \mathrm{rack} \text { densities. }\end{array}$ & $\begin{array}{l}\text { It is possible to handle the rack density } \\
\text { from } 20 \mathrm{~kW} / \text { rack up to } 100 \mathrm{~kW} / \mathrm{rack} \\
\text { within a liquid cooling. }\end{array}$ \\
\hline 4. & Serviceability & $\begin{array}{l}\text { Air cooling system is older and } \\
\text { wider process but in compare to } \\
\text { liquid cooling its serviceability } \\
\text { is poor. }\end{array}$ & $\begin{array}{l}\text { IT staff must apply the new approaches } \\
\text { for the purpose of maintenance of the IT } \\
\text { equipment as they can be benefited from } \\
\text { the reduction of power and cooling } \\
\text { equipment for service and maintenance. }\end{array}$ \\
\hline 5. & Water Usage & $\begin{array}{l}\text { There is a big worldwide problem } \\
\text { regarding the high volume of water } \\
\text { consumption by many of the } \\
\text { air-cooled data centers as this } \\
\text { centers depend on evaporative } \\
\text { cooling with cooling towers for } \\
\text { achieving the low PUEs. }\end{array}$ & $\begin{array}{l}\text { Although the evaporative cooling can } \\
\text { be eliminated or drastically reduced due } \\
\text { to use of warm water with } 45^{\circ} \mathrm{C} / 113^{\circ} \mathrm{F} \\
\text { and sometimes higher but it still } \\
\text { achieving high efficiency. }\end{array}$ \\
\hline 6. & Harsh environment & It can't be paced anywhere & $\begin{array}{l}\text { The airflow is not required by the } \\
\text { immersive liquid cooling and it is closed } \\
\text { from the outside elements that provide a } \\
\text { capability to be placed almost anywhere. }\end{array}$ \\
\hline 7. & $\begin{array}{l}\text { Fan noise / air } \\
\text { movement }\end{array}$ & $\begin{array}{l}\text { It generates noise due to CRAH } \\
\text { fan speed. }\end{array}$ & $\begin{array}{l}\text { It generates less noise and in case of } \\
\text { Immersion cooling to noise due to no } \\
\text { Fan. }\end{array}$ \\
\hline 8. & Room layout & It is not feasible & $\begin{array}{l}\text { Within data centre, it offers bigger } \\
\text { flexibility as not required white space } \\
\text { and also the arrangement of hot/cold } \\
\text { aisle is not essential for it for a long } \\
\text { time. It is also possible the Back-to-back } \\
\text { rows in this system. }\end{array}$ \\
\hline
\end{tabular}


Table 4: Merits and demerits of different cooling techniques

\begin{tabular}{|c|c|c|}
\hline Different cooling Techniques & Merits & Demerits \\
\hline CRAC and air cooled Condenser & $\begin{array}{l}\text { - Lower Capital cost. } \\
\text { - Easy to maintain. }\end{array}$ & 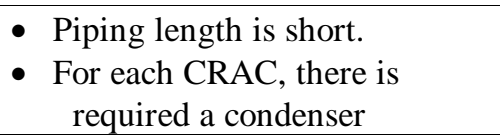 \\
\hline The Units of Chilled Water CRAH & $\begin{array}{l}\text { - Low rate of cost, } \\
\text { - Contain fewer parts with the } \\
\text { ability to remove greater } \\
\text { heat. } \\
\text { - The capacity and utility of the } \\
\text { data centre can be improved } \\
\text { significantly by the } \\
\text { efficiency of the chilled } \\
\text { water system. } \\
\text { - The method of chilled water } \\
\text { piping loops can cover } \\
\text { elongated distances very } \\
\text { easily and can serve within } \\
\text { many IT platforms. } \\
\text { - Very reliable. } \\
\text { - Very Efficient. }\end{array}$ & $\begin{array}{l}\text { - Maximum capital costs. } \\
\text { - It approaches an extra origin of } \\
\text { liquid within the IT } \\
\text { atmosphere. }\end{array}$ \\
\hline Immersion Cooling & $\begin{array}{l}\text { - Coolant pumps are not } \\
\text { required (although water } \\
\text { pumps or cooling towers } \\
\text { are still required). } \\
\text { - Due to quick evaporation of } \\
\text { coolant in atmosphere, the } \\
\text { ardware can be easily } \\
\text { re-used. } \\
\text { - It is Biodegradable coolant } \\
\text { (human and environment } \\
\text { hazardous free) and } \\
\text { compatible with fibre optics. }\end{array}$ & $\begin{array}{l}\text { - It is considered a financially } \\
\text { non-viable for the Data } \\
\text { Centre due to its high price of } \\
\text { the two-phase coolant } \\
\text { - High-volatility of the coolant in } \\
\text { gas form. }\end{array}$ \\
\hline Evaporative cooling & $\begin{array}{l}\text { - } \text { Erergy efficient } \\
\text { - It generates fresh air } \\
\text { - Environment friendly } \\
\text { - Lower initial and ongoing } \\
\text { cost }\end{array}$ & $\begin{array}{l}\text { - The cooling capability of } \\
\text { the evaporative cooler } \\
\text { decreases with the high } \\
\text { humidity. } \\
\text { - In comparison with Air } \\
\text { conditioning system it can } \\
\text { unable to lower temperature. }\end{array}$ \\
\hline Direct/Indirect Free cooling & $\begin{array}{l}\text { - Sometimes it will be efficient } \\
\text { - Cost is lower }\end{array}$ & $\begin{array}{l}\text { - It is not feasible all the time. } \\
\text { - It sometimes need filtration } \\
\text { process at this point it will } \\
\text { costly. }\end{array}$ \\
\hline Renewable Cooling Technology & $\begin{array}{l}\text { - Provides predictable and often } \\
\text { fixed-price energy } \\
\text { - Reduces emissions and air } \\
\text { pollutants without } \\
\text { sacrificing comfort or } \\
\text { performance }\end{array}$ & $\begin{array}{l}\text { - High upfront cost } \\
\text { - Geographic limitations. }\end{array}$ \\
\hline
\end{tabular}




\begin{tabular}{|l|l|l|}
\hline & $\begin{array}{l}\text { Maintenance requirements } \\
\text { lower. }\end{array}$ & \\
\hline AI Cooling technique & $\bullet$ Increases cooling Efficiency & $\begin{array}{l}\bullet \text { Interpretation of results } \\
\bullet \text { High error suspectability }\end{array}$ \\
$\bullet$ Lights out automation & $\bullet$ More High density servers \\
& $\begin{array}{l}\text { Equipment management is } \\
\text { better }\end{array}$ \\
\hline
\end{tabular}

\section{FUTURE CHALLENGES AND SOME SOLUTIONS}

According to Koronen et al.[82], there are some important characteristics of future renewable energy systems like end-use efficiency, liking of various energy vectors and demand response. Increase of data centres may increase the demand of electricity and also rise the new electricity-intensive industry. As reported by Koutitas et al.[83], the investigates challenges for reaching the efficiency of energy in local and regional data centres and the challenges are categorized into operational and planning categories which must be considered for the green transformation of the data centre. According to the study, to control the discharge of carbon generated form the data centres, it is required the standardization of the used metrics and guidelines as the data centres are recognized as a primary consumers of huge amount of energy, consumed by the IT and server room air conditioning peripherals and equipment and also by general building facilities. According to Dirk Pesch et al. [84], the requirements for IT devices and for cooling purposes are considered as the most key and challenging factors for a data centre which are not always in synchronized position and not possible to coordinate always and it leads less optimized energy consumption. Although it is always preferable to obtain the system with integrated energy that jointly helps to optimizes and controls all its equipment that consume the energy for reducing energy consumption and raise the usage of local sources of renewable energy accordingly. According to [82], in the data centre industry, there are significant approach which promises a system integrated with well-developed efficiency and an extendable energy system. Maximum efforts of both the developer of policy-makers and the current industry are significant and urgently required in future to control and capture this potential and to get the advantages of efficiency and flexibility of the energy system. According to [83], for both the noncritical and IT equipment, the energy efficiency should target overall system optimization with key attention placed on cooling, power delivery systems, virtualization and workload management. As per the report of [84], to cope with the challenges of optimization problem that arises for the lack of coordination of According to [85], it is expected to maximize the energy consumption share of the network portion. A concerted and dedicated efforts are required in a data centres for the ever-increasing and rising the share of the network energy consumption for saving the important and major part of energy by full utilizing of overprovisioning vacuity of the equipment related to network.

As proposed by Anuj Kumar Yadav et al. [86], few parameters like Server scheduling, QoS (Quality of service), network topology, workload scheduling, virtual machine migration, waste heat utilization, load balancing etc. have been considered by their approach. Depending on comparative study of all the solutions, provided by the researchers, a new algorithm can be developed that allow the high energy efficiency and low $\mathrm{CO}_{2}$ emission and without reduction the QoS in cloud computing.

As reported in [87], there are some very important future challenges of data centres, namely, Reduce Cooling Dependencies, Experiment with Temperatures, Synchronize Server Capacity and Load, Identify and Kill Zombie Servers, Decrease or Optimize Space, Find Stronger Supplier Partnerships. Now a day, cooling system is one of the biggest and serious challenges for modern data centre. Modern IT system has introduced new cooling related problems [88] and some of the challenges in the data center cooling process are Availability, Manageability, Lifecycle costs, Adaptability, Maintenance etc. Adaptability requirements are considered as one of the major challenge for many of the data centre, regarding cooling. These challenges include the hazards related to cooling of high density rack system and also contain uncertainty of timing, location and quantity of it. In a data centre, the cooling system should maintain the features of scalability and flexibility and also the feature of redundant cooling for maintaining the consistency and stable performance. It is quite difficult to predict the future load of a data centre cooling system by the Data centres even the prediction of load characteristic offer bigger challenge. After established a suitable and appropriate design, the data centres have to perform the best cooling practices, enlisted bellow:

\subsection{To Determine the Critical Load and Heat Load}

The data centres can get the information regarding the quantity of the cooling systems that are required to installed and arranged within the existing and available space by the help of determining load. In this regard, the companies should include the heat that conducted from adjacent places. 


\subsection{Establish the requirements of Power as per Rack Location Unit (RLU)}

Depending on the number of available cabinets or racks in data centres, the power thickness of data centre is defined. Usually all the manufacturers produce cabinets are of equal size. The power density of RLU can be delivered by Rack Location Unit which is growing each and every year and predicting the cooling for the variable RLU densities. Is one of the big challenges for data centre?

\subsection{Determine Room Power Distribution}

Two major decisions regarding the determining of the room power distribution are where to place PDU (Power Distribution Units) and the location for running the power cables, either under or over the floor.

\subsection{To determine the Cabinet Power Distribution}

This is important to recognize the effect of the supply and distribution of the power on cooling as within the cabinets, it is connected with the concept of air flow.

\subsection{To Determine the Appropriate Cooling Methodology}

For a data centre, the suitable type of air conditioners can be decided after determining the cooling zones. There are four different types of the air conditioners, namely, the Air cooler, the condenser water cooler, glycol cooler and the Chilled cooler. Apart from these, the managers belongs to the data centre should control the method for removing the heat from data centre and also they should determine the natures of cooling redundancy that will be essential for a specific technique.

\subsection{Establish Cooling Performance Monitoring System}

To develop and organize a monitoring system is essential and important for data centre. This system can monitor the cooling zone of every single cabinet and also able to watch the rows and each rooms of the system. The system allows some changes that can be expected if a specific load profile will get an active cooling performance once. Therefore it is appropriate to include all the parameters for changing, adding or moving that equipment quickly to provide the changes.

To reduce the data centres cooling demand is the most challenging factor. According to Kaylie Gyarmathy [89], there are some factors that increase the data centre cooling. These are -

\subsubsection{The Bad Cabinet Layout}

There should be a cold and hot aisle DC cooling design attached with a good cabinet layout at the end of each row of the air handlers of computer room. It is not an efficient manner to use the configuration of an island without arranging a well-organized orientation.

\subsubsection{Empty Cabinets}

To leak back into cold aisle the vacant cabinets allow the warm and exhaust air by skewing the airflow. The presence of empty cabinets denotes the contained of the cold air.

Empty Spaces between Equipment: The empty, uncovered spaces cabinets between the hardware can ruin airflow management. Therefore it is necessary to seal the spaces in the cabinet as the hot air can leak back into the cold aisle and whether the spaces are sealed or not that will be checked by a conscientious operator.

\subsubsection{Raised Floor Leaks}

Under some circumstances, the raised floor leaks may occur if there will be any leakage of cold water under the raised floor or adjacent spaces or support columns.

Leaks around Cable Openings

Due to the arrangement of cable management, a lot of openings in cabinets' floors of data centres can be found. These openings are under the raised floor inspecting for leaks and also can generate open cabling system as well as many holes within the power distribution cells which leads a situation in which the cold air escape.

\subsubsection{Multiple Air Handlers Fighting to Control Humidity}

A lot of wasted energy can be a result of a situation where the two units fight for control in this manner that when one air handler will try to dehumidify the air then another unit will try to humidify the same air and this occurrence can be reduced by thoroughly planning humidity control points.

According to [67], the data centres utilize $75 \%$ more cooling than needed [91]. As reported by [92], cooling a data centre is not smooth and safe but it is for risk management although amount of money spent on cooling is more than required. The data centres can be benefited by the smart assistance like Adept DC to save the cost as it allows the data centre managers to get this information that when and how much cooling is required. To study the processes the data and to read the temperature of CPU and GPU, it implements the smart cooling and machine learning concept which helps the data centres for developing much more efficient. For monitoring the temperature and humidity levels of the server from the inside of the cabinet one of the attractive and innovative approach is the data centre cooling robot. By placing the One Neck robot sensor in the bottom of the cabinet can be an effective approach for scanning the heat and humidity levels along with moving it to the top and back down again. By the implementation of this approach, one can monitor the heat and humidity levels through the smart device without opening the cabinet. In spite of cooling the entire data 
centre, the said technology also allows the managers to cool only the required areas in a smart and efficient manner [91].

According to CBINSIGHTS [90] the data centre current, tomorrow and future trends are discussed below-

Table 5: Future trends of Green Cloud C

\begin{tabular}{|c|c|c|c|}
\hline Parameter & Today & Tomorrow & Future \\
\hline Location & $\begin{array}{l}\text { Near Fibre } \\
\text { Networks }\end{array}$ & $\begin{array}{l}\text { Cool stable } \\
\text { climates }\end{array}$ & $\begin{array}{c}\text { Small and } \\
\text { off-shore } \\
\text { data } \\
\text { centres }\end{array}$ \\
\hline Structures & $\begin{array}{l}\text { Cloud and } \\
\text { on-premise }\end{array}$ & $\begin{array}{l}\text { Smaller and } \\
\text { larger }\end{array}$ & $\begin{array}{c}\text { No Data } \\
\text { centres at } \\
\text { all }\end{array}$ \\
\hline $\begin{array}{l}\text { Energy } \\
\text { Efficiency }\end{array}$ & $\begin{array}{l}\text { Air based } \\
\text { cooling }\end{array}$ & $\begin{array}{l}\text { Liquid and AI } \\
\text { assisted } \\
\text { cooling }\end{array}$ & $\begin{array}{l}\text { Reusing of } \\
\text { excess heat }\end{array}$ \\
\hline Renewables & $\begin{array}{l}\text { Plugged in } \\
\text { and RECs }\end{array}$ & $\begin{array}{l}\text { Big tech Buys } \\
\text { Renewables }\end{array}$ & $\begin{array}{c}\text { RE farms } \\
\text { and Data } \\
\text { centres } \\
\text { work } \\
\text { together }\end{array}$ \\
\hline Storage & HDD & SSD & $\begin{array}{c}\text { HAMR } \\
\text { and Liquid } \\
\text { state } \\
\text { storage. }\end{array}$ \\
\hline
\end{tabular}

\section{CONCLUSION AND FUTURE CHALLENGES}

At present, one of the biggest threat for our environment is the heat, generated by the millions of servers in data centres. In this survey paper, we are trying to depict the analytical report on the effectiveness and energy efficiency of the data centre along with the advantages and disadvantages of various modern and emerging cooling technologies. A list of effective data centre efficiency method, along with problem definition and solution which already defined in some papers, has been referred here. In this modern and technical world where the data centres are becoming the essential and integral part of our world and subsequently the implementation of the concept of strong and efficient cooling system is taking a great part for ecosystem as the data centres are generating huge amount of heat due to the continuous use of the huge number of computers at enormously high rates. In this paper, as the methods of cooling the data centres, highlighted on some new smart techniques like immersion cooling, evaporation cooling or swamp cooling over the traditional cooling systems like air based cooling system and liquid based cooling system. Different organisations are trying to establish the new innovative inventions for changing the settings of data centre cooling, namely, Google's environmentally friendly data centre where in Hamina, Finland, the search engine company is utilizing seawater for cooling their data centre and this system allows the use of cold water to cool the mechanism, instead of burning any carbon to cool. Apart from this, through this system, also the Facebook utilizes the captured rainwater for cooling their data centre. The AI technology is also considered as important innovations for cooling the data centres. The Data centre cooling robot is another attractive and innovative technique monitoring and controlling the temperature and humidity levels of a Data centre. Therefor gradually the cooling system is considered as the integral part of the ecosystem of our nature that needs more and more efficient and innovative methods to protect our nature from global warming effects and establish a greener world. In this paper we discussed all these cooling technology in brief and try to draw the future challenges and scopes of data centres energy efficiency and cooling technique. Finally, our aim of this paper is to help the researchers in future to fabricate a new method for establishing the innovative cooling system in an efficient manner from the already developed effective and successful methods that discussed here.

\section{REFERENCES}

1. Cloud computing energy efficiency. Available at https://www.pikeresearch.com/research/cloud-computin g-energy-efficiency (Accessed on 01.06.20).

2. Laura Diana Radu., Green Cloud Computing: A Literature Survey. Symmetry, MDPI, 9(12), November 2017.

3. Data Center Electricity Use 2005 to 2010. Available online: http://www.analyticspress.com/datacenters.html (accessed on 12 June 2016).

4. The Role of ICT in Driving a Sustainable Future. 2013. Available online: http://gesi.org/SMARTer2020 (accessed on 2 November 2016).

5. A.D. Borah, D. Muchahary, S.K. Singh, and J. Borah, Power Saving Strategies in Green Cloud Computing Systems. International Journal of Grid Distribution Computing, Vol.8, No.1 pp.299-306, 2015.

6. Smart 2020: Enabling the low carbon economy in the information age. Available online: https://www.theclimategroup.org/sites/default/files/arch ive/files/Smart2020Report.pdf, (accessed on June 2008).

7. Sarddar, D., Roy, S., and Bose, R. (2014). An Efficient Edge Servers Selection in Content Delivery Network Using Voronoi Diagram. IJRITCC, Vol. 2, No. 8, pp. 2326-2330, 2014.

8. How Data Center Free Cooling Works and Why it is Brilliant. Available at https://www.masterdc.com/blog/what-is-data-center-fre e-cooling-how-does-it-work/ (Accessed on 18.11.2015).

9. Data Center Cooling Technology. available at https://www.vxchnge.com/blog/data-center-cooling-tech nology (Accessed on 17.01.20).

10. R.D. Viroja, and D.H. Viroja, Energy Saving by Virtual Machine Migration in Green Cloud Computing, International Journal of Trend in Scientific Research and Development, Volume 1, No. 1, December 2016. 
11. K. Usvub, A.M. Farooqi, and M.A. Alam, Edge Up Green Computing in Cloud Data Centers. International Journal of Advanced Research in Computer Science, Vol. 8, No. 2, 2017.

12. B. Saha, Green computing: current research trends. International Journal of Computer Sciences and Engineering, Vol. 6, No. 3, pp. 467-469, 2018.

13. V. Kharchenko, and O. Illiashenko, Concepts of green IT engineering: taxonomy, principles and implementation. In Green IT Engineering: Concepts, Models, Complex Systems Architectures, pp. 3-19, Springer, Cham, 2017.

14. N.S. More, and R.B. Ingle, Challenges in green computing for energy saving techniques. In 2017 International Conference on Emerging Trends \& Innovation in ICT (ICEI) pp. 73-76, IEEE, February, 2017.

15. P. Sharma, P. Pegus II, D. Irwin, P. Shenoy, J. Goodhue and J. Culbert, Design and Operational Analysis of a Green Data Center. in IEEE Internet Computing, Vol. 21, No. 4, pp. 16-24, 2017, doi: 10.1109/MIC.2017.2911421.

16. M. Mesaad, H. Alansari, M. Ahgamdi, B.S. Saad, and M. Hemalatha, Survey on the Global Green Computing Initiatives. International Journal of Computer Applications, Vol. 167, pp. 42-45, 2017.

17. I. AlMusbahi, O. Anderkairi, R.H. Nahhas, B. AlMuhammadi, and M. Hemalatha, M. (2017). Survey on Green Computing: Vision and Challenges. International Journal of Computer Applications, Vol. 167, pp. 4-6, 2017.

18. E. Kern, Green Computing, Green Software, and Its Characteristics: Awareness, Rating, Challenges. From Science to Society. Springer, Cham, pp. 263-273, 2018.

19. W. Fisher, M. Suchara, and J. Rexford, Greening backbone networks: reducing energy consumption by shutting off cables in bundled links, in Green Networking, pp. 29-34, 2010.

20. D. Kliazovich, P. Bouvry, and S. Khan, DENS: Data Centre Energy- Efficient Network-Aware Scheduling, in Green Computing and Communications (GreenCom), pp. $69-75,2010$.

21. A. M. Farooqi, Comparative Analysis of Green Cloud Computing, International Journal of Advanced Research in Computer Science, Volume 8, No. 2, 2017.

22. H. Ibrahim, R.O. Aburukba, K. El-Fakih, An Integer Linear Programming model and Adaptive Genetic Algorithm approach to minimize energy consumption of Cloud computing data centers, Computers \& Electrical Engineering, Volume 67, pp. 551-565, 2018.

23. R. Lin, and Y. Deng, Allocating workload to minimize the power consumption of data centers. Frontiers of Computer Science, Vol. 11, No. 1, pp. 105-118, 2017.

24. T. Antonios, K. C. Makaratzis, F.-Papadopoulos, K. M. Giannoutakis, G. A. Gravvanis, and D. Tzovaras. A comparative study of CPU power consumption models for cloud simulation frameworks, In
Proceedings of the 21st Pan-Hellenic Conference on Informatics (PCI 2017). Association for Computing Machinery, New York, NY, USA, Article 10, pp. 1-6, 2017.

25. B. Bisoyi, B. Das, Necessitate Green Environment for Sustainable Computing. In: Satapathy S., Raju K., Mandal J., Bhateja V. (eds) Proceedings of the Second International Conference on Computer and Communication Technologies. Advances in Intelligent Systems and Computing, Vol 380. Springer, New Delhi, 2016.

26. W. Binder, N. Suri, Green Computing: Energy Consumption Optimized Service Hosting. In: Nielsen M., Kučera A., Miltersen P.B., Palamidessi C., Tůma P., Valencia F. (eds) SOFSEM 2009: Theory and Practice of Computer Science. SOFSEM 2009. Lecture Notes in Computer Science, Vol 5404. Springer, Berlin, Heidelberg.

27. T. L. Vinh, R. Pallavali, F. Houacine, and S. Bouzefrane, Energy Efficiency in Mobile Cloud Computing Architectures. 2016 IEEE 4th International Conference on Future Internet of Things and Cloud Workshops (FiCloudW), Vienna, pp. 326-331, 2016.

28. S. Saxena, A. Kumar, and R. Johri, Analytical Study of Computing in Green Environment. International Journal of Innovative Research in Engineering \& Management, Vol. 4, No. 5, pp. 740-742, 2017.

29. S. Rawas, W. Itani, A. Zaart, and A. Zekri, Towards greener services in cloud computing: Research and future directives. 2015 International Conference on Applied Research in Computer Science and Engineering (ICAR), Beirut, pp. 1-8, 2015.

30. J. Weixiang, J. Ziyang, F. Sirui, L. Fangming, and H. Jin. Fine-grained warm water cooling for improving datacenter economy. In Proceedings of the 46th International Symposium on Computer Architecture (ISCA '19). Association for Computing Machinery, New York, NY, USA, pp. 474-486, 2019.

31. J. B. Marcinichen, J. A. Olivier, J. R. Thome, On-chip two-phase cooling of datacenters: Cooling system and energy recovery evaluation, Applied Thermal Engineering, Volume 41, pp. 36-51, 2012.

32. X. Zhang, T. Lindberg, N. Xiong, V. Vyatkin, Cooling Energy Consumption Investigation of Data Center IT Room with Vertical Placed Server, Energy Procedia, Vol. 105, pp. 2047 - 2052, 2017.

33. H. Moazamigoodarzi, P. J. Tsai, S. Pal, S. Ghosh, I. K. Puri, Influence of cooling architecture on data centre power consumption, Energy, Vol.183, pp. 525-535, 2019.

34. I.W. Kuncoro1, N.A. Pambudi, M.K. Biddinika, I Widiastuti, M. Hijriawan, and K M Wibowo, Immersion cooling as the next technology for data center cooling: A review, 4th Annual Applied Science and Engineering Conference Journal of Physics: Conference Series, Vol. 1402, No. 044057, IOP Publishing, pp. 1-5, 2019. 
35. J. Yu, Y. Jiang, Y. Yan, A simulation study on heat recovery of data center: A case study in Harbin, China. Renewable Energy, Vol. 130, pp. 154-173, 2019.

36. C. Koronen, M. Åhman, and L.J. Nilsson, Data centres in future European energy systems-energy efficiency, integration and policy. Energy Efficiency, Vol. 13, pp. 129-144, 2020.

37. J. Wan, X. Gui, S. Kasahara, Y. Zhang, R. Zhang, Air Flow Measurement and Management for Improving Cooling and Energy Efficiency in Raised-Floor Data Centers: A Survey. IEEE Access, Vol. 6, pp. 48867 48901, 2018.

38. J. VanGilder, Y. Jhang, S. Linder, M. Condor, S. Electric, Balancing Cooling and IT Airflow with Dampers in Ceiling-Ducted Hot-Aisle Containment in Data Centres. 2019 18th IEEE Intersociety Conference on Thermal and Thermomechanical Phenomena in Electronic Systems (ITherm), Las Vegas, NV, USA, pp. 1282-1288, 2019.

39. W. Zhang, Y. Wen, Y. Wah Wong, K. Chuan Toh, and C. Chen, Towards Joint Optimization Over ICT and Cooling Systems in Data Centre: A Survey. IEEE Communications Surveys \& Tutorials, Vol. 18, No. 3, pp. 1596-1616, 2016.

40. L. A. Campbell, R. C. Chu, M. P. DAVID, M.J. Ellsworth, Jr. M. K. Iyengar, R. R. Schmidt, R. E. Simons, Data center cooling with an air-side economizer and liquid-cooled electronics $\operatorname{rack}(\mathbf{s})$. US9101078B2, 2011.

41. J. David Hay, MULTI-MODE COOLING SYSTEM AND METHOD WITH EVAPORATIVE COOLING. US20100154448, 2010.

42. R. TOZER, L. NEVILLE, Data centre and apparatus and method for data centre cooling. US8634963B2, United States.

43. T. Staedter, A Cooler Cloud: A Clever Conduit Cuts Data Centers' Cooling Needs by 90 Percent. IEEE SPECTRUM, 2019.

44. L. Yao, J.-H. Huang, Multi-Objective Optimization of Energy Saving Control for Air Conditioning System in Data Center. Energies, Vol. 12, No. 8, pp. 1-16, 2019.

45. Y. Li, Y. Wen, D. Tao, and K. Guan, Transforming Cooling Optimization for Green Data Center via Deep Reinforcement Learning. IEEE Transactions on Cybernetics, Vol. 50, No. 5, pp. 2002-2013, 2020.

46. A. Capozzolia, G. Primiceria, Cooling systems in data centers: state of art and emerging technologies. Energy Procedia, Vol. 83, pp. 484-493, 2015.

47. G. Zhabelova, M. Vesterlund, S. Eschmann, Y. Berezovskaya, V. Vyatkin, and D. Flieller, A Comprehensive Model of Data Center: From CPU to Cooling Tower. IEEE Access, Vol. 6, pp. 61254-61266, 2018.

48. R. Bose, S. Roy, and D. Sarddar, A Billboard Manager Based Model That Offers Dual Features Supporting Cloud Operating System And Managing Cloud Data
Storage. Int. J. of Hybrid Info. Tech. (IJHIT), Vol. 8, pp. 229-236, 2015.

49. R. Bose, S. Chakraborty, and S. Roy, Explaining the workings principle of cloud-based multi-factor authentication architecture on banking sectors. In 2019 Amity International Conference on Artificial Intelligence (AICAI), pp. 764-768, 2019.

50. C. Roy Chowdhury, A. Chatterjee, A. Sardar, S. Agarwal, A. Nath. A Comprehensive study on Cloud Green Computing: To Reduce Carbon Footprints Using Clouds. International Journal of Advanced Computer Research, Vol. 3, No. 3, pp.78-85, 2013.

51. R. Yadav, W. Zhang, K. Li, C. Liu, M. Shafiq, N. K. Karn, An adaptive heuristic for managing energy consumption and overloaded hosts in a cloud data center. Wireless Network, Vol. 26, pp. 1905-1919, 2018.

52. S. Saxena, and D. Saxena, Green Cloud Computing Architecture with Efficient Resource Allocation System. International Journal of Trend in Research and Development, Vol. 3, No. 6, pp. 248-251, 2016.

53. A. Carrega, and M. Repetto, Exploiting Novel Software Development Paradigms to Increase the Sustainability of Data Centers. 2016 IEEE/ACM 9th International Conference on Utility and Cloud Computing (UCC), Shanghai, pp. 310-315, 2016.

54. G. Procaccianti, P. Lago, S. Bevini, A systematic literature review on energy efficiency in cloud software architectures. Sustainable Computing: Informatics and Systems, Vol. 7, pp. 2-10, 2015.

55. A. Pahlevan, M. Rossi, P. G. D. Valle, D. Brunelli, and D. Atienza, Joint Computing and Electric Systems Optimization for Green Datacenters. Handbook of Hardware/Software Codesign, pp. 1163-1183, 2017.

56. F. K. Shaikh, S. Zeadally, and E. Exposito, Enabling Technologies for Green Internet of Things. IEEE Systems Journal, Vol. 11, No. 2, pp. 983-994, 2017.

57. Y. Sharma, B. Javadi, W. Si, D. Sun, Reliability and energy efficiency in cloud computing systems: Survey and taxonomy. Vol. 74, pp. 66-85, 2016.

58. A. Sofia, Sathya, and P. Ganesh Kumar. Energy efficient task scheduling to implement green cloud. Asian Journal of Research in Social Sciences and Humanities, Vol. 7, No. 2, pp. 443-458, 2017.

59. S. Roy, R. Bose, and D. Sarddar. Self-servicing energy efficient routing strategy for smart forest. Brazilian Journal of Science and Technology, Vol. 3, No. 1, pp. 1-21, 2016.

60. F. Satoh, H. Yanagisawa, H. Takahashi and T. Kushida, (Eds.), Total Energy Management system for Cloud Computing. Proceedings of the IEEE International Conference of the Cloud Engineering (IC2E), Redwood City, CA, pp. 233-240, 2013.

61. T. Day, P. Lin, R. Bunger, Liquid Cooling Technologies for Data Centers and Edge Applications. White Paper 265, Schneider, pp. 1-12, 2019.

62. K. Heslin, A Look at Data Center Cooling Technologies. UptimeInstitute, pp. 1, 2015. 
63. S. Roy, R. Bose, T. Roy, and D. Sarddar. Cloud-enabled data center organization using KD tree. International Journal of Database Theory and Application, Vol. 8, No. 3, pp. 69-76, 2015.

64. Tony Evans, The Different Technologies for Cooling Data Centers. White Paper 59, pp. 1-16, 2012.

65. Y. Zhang, Z. Wei, M. Zhang, Free cooling technologies for data centers: energy saving mechanism and applications, World Engineers Summit - Applied Energy Symposium \& Forum: Low Carbon Cities \& Urban Energy Joint Conference, WES-CUE 2017, 2017, Singapore.

66. A. Capozzoli, G. Primiceri, Cooling systems in data centers: state of art and emerging technologies. 7th International Conference on Sustainability in Energy and Buildings, Energy Procedia, Vol. 83, pp. 484 - 493, 2015.

67. M. Isberto, How Data Center Cooling is Changing. Data Center News, 2018.

68. R. R. Schmidt, E.E. Cruz, M.K. Iyengar. Challenges of data center thermal management. IBM J Res Dev; Vol. 49, No. 4/5, pp. 709-23, 2005.

69. A. Capozzoli, M. Chinnici, M. Perino, G. Serale. Review on Performance Metrics for Energy Efficiency in Data Center: The Role of Thermal Management. LECT NOTES COMPUT SC, Vol. 8945, pp 135-151, 2015.

70. A. Capozzoli, G. Serale, L. Liuzzo, M. Chinnici, Thermal Metrics for Data Centers: A Critical Review. Energy Procedia, Vol. 62, pp. 391-400, 2014.

71. J. Cho, J. Yang, W. Park. Evaluation of air distribution system's airflow performance for cooling energy savings in high-density data centers. Energ Buildings, Vol. 68, pp. 270-279, 2014.

72. T. Lu, X. Lü, M. Remes., M. Viljanen. Investigation of Air Management and Energy Performance in a Data Center in Finland: Case study. Energ Buildings, Vol. 43, No. 12, pp. 3360- 3372, 2011.

73. J. Niemann, K. Brown, V. Avelar. Impact of Hot and Cold Aisle Containment on Data Center Temperature and Efficiency. APC White Paper, Vol. 135, 2011.

74. K. Dunlap, N. Rasmussen. Choosing Between Room, Row, and Rack-based Cooling for Data Centers. APC White Paper, Vol. 130, 2012.

75. A. Almoli, A. Thompsion, N. Kapur, J. Summers, H. Thompson, G. Hannah. Computational fluid dynamic investigation of liquid rack cooling in data centres. Appl Energ, Vol. 89, pp. 150-155, 2012.

76. YQ Chi, J. Summers, P. Hopton, K. Deakin, A. Real, N. Kapur, H. Thompson. Case Study of a Data Centre Using Enclosed, Immersed, Direct Liquid-cooled Servers. In: Proceedings of the 30th IEEE SEMI-THERM symposium. San Jose (CA, USA); pp. 164-173, 2014.

77. R. Bose, S. Roy, and D. Sarddar, On Demand IOPS Calculation in Cloud Environment to Ease
Linux-Based Application Delivery. In Proceedings of the First International Conference on Intelligent Computing and Communication. Springer, Singapore, pp. 71-77, 2017.

78. H. Zhang, S. Shao, H. Xu, H. Zou, C. Tian. Free cooling of data centers: A review. Renew Sust Energ Rev, Vol. 35, pp. 171-182, 2014.

79. Evaporative Cooling Solution for Data Centers. Available at https://www.buildings.com/news/industry-news/articlei d/21649/title/evaporative-cooling-data-center (Accessed on 22.08.20).

80. K. Ebrahimi, G.F. Jones, A.S. Fleischer. A review of data center cooling technology, operating conditions and the corresponding low-grade waste heat recovery opportunities. Renew Sust Energy Rev, Vol. 31, pp. 622-638, 2014.

81. J. Gao, Machine Learning Applications for Data Center Optimization. Available at https://static.googleusercontent.com/media/research.goo gle.com/en//pubs/archive/42542.pdf (Accessed on 22.08.20).

82. C. Koronen, M. Åhman, and L.J. Nilsson, Data centres in future European energy systems-energy efficiency, integration and policy. Energy Efficiency, Vol. 13, pp. 129-144, 2020.

83. G. Koutitas, P. Demestichas, Challenges for energy efficiency in local and regional data centers", Journal of Green Engineering. Journal of Green Engineering, pp. 1-32, 2010.

84. D. Pesch, S. Rea, J. Ignacio Torrens, V. Zavrel, J.L.M. Hensen, D. Grimes, B. O'Sullivan, T. Scherer, R. Birke, L. Chen, T. Engbersen, L. Lopez, E. Pages, D. Mehta, J. Townley, and V. Tsachouridis, Globally Optimised Energy-Efficient Data Centres. ICT - Energy Concepts for Energy Efficiency and Sustainability, 2017.

85. N. Jones, How to stop data centres from gobbling up the world's electricity. Nature. Available at https://www.nature.com/articles/d41586-018-06610-y (Accessed on 22.08.20).

86. A. K. Yadav, M.L. Garg, and Ritika. The Issues of Energy Efficiency in Cloud Computing Based Data Centers. Bioscience Biotechnology Research Communications, Vol. 12, No. 2, 2019.

87. A. Marashi, Improving Data Center Power Consumption \& Energy Efficiency. Available at https://www.vxchnge.com/blog/growing-energy-deman ds-of-data-centers (Accessed on 22.08.20).

88. Challenges of Cooling Data Centers. Available at http://www.datacentertalk.com/2015/09/challenges-of-c ooling-data-centers/ (Accessed on 22.08.20).

89. K. Gyarmathy. What You Should Know About Data Center Cooling Technologies. VXCHNGE. Available at https://www.vxchnge.com/blog/data-center-cooling-tech nology (Accessed on 22.08.20). 
90. The Future of Data Centers. Available at https://www.cbinsights.com/research/future-of-data-cent ers/ (Accessed on 22.08.20).

91. R. Bose, S. Roy, and D. Sarddar. On Demand IOPS Calculation in Cloud Environment to Ease Linux-Based Application Delivery. In Proceedings of the First International Conference on Intelligent Computing and Communication, Springer, Singapore, pp. 71-77 2017.

92. S. Roy, R. Bose, and D. Sarddar. Non-recursive inorder traversal on constructed threaded KD tree for efficient cloud based space partitioning. In 2015 International Conference on Advances in Computer Engineering and Applications, IEEE, pp. 665-668. 2015. 